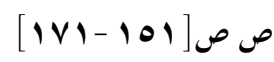

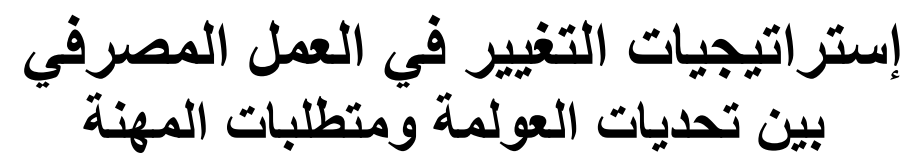

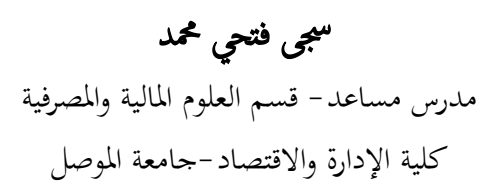

Muy2ms@yahoo.com

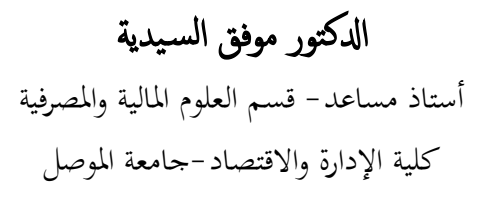

Alsaydia1@yahoo.com

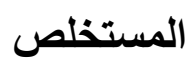

يعد العمل المصرفي واحداً من أبرز النشاطات التي تفاعلت مع التطورات الدولية ولات سيما

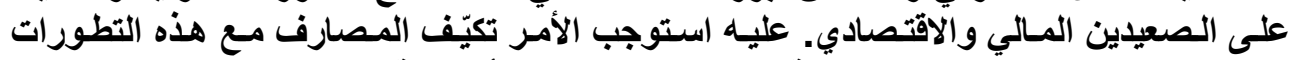

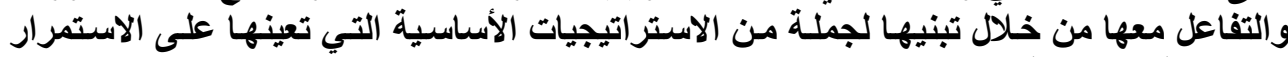

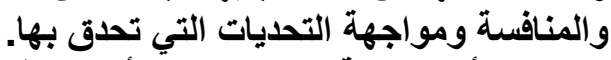

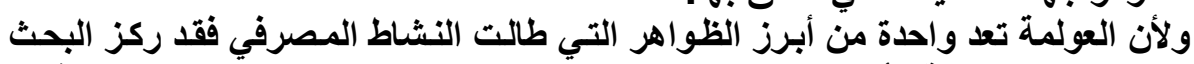

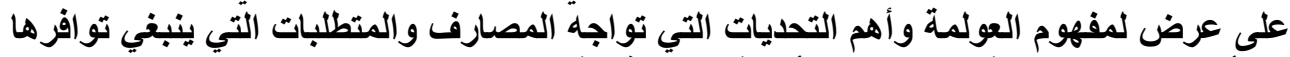

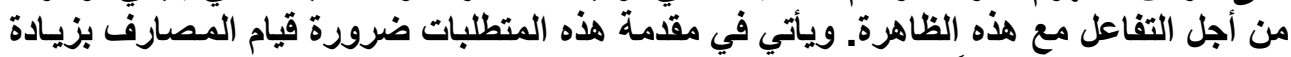

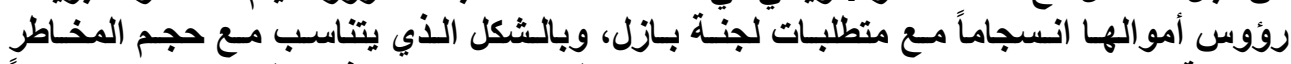

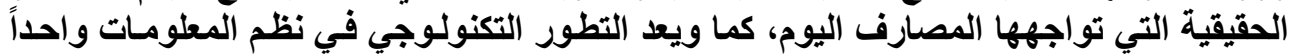

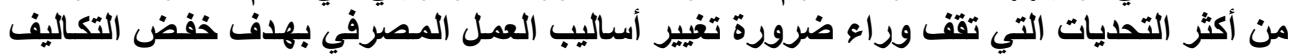

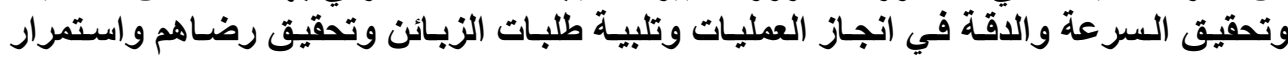

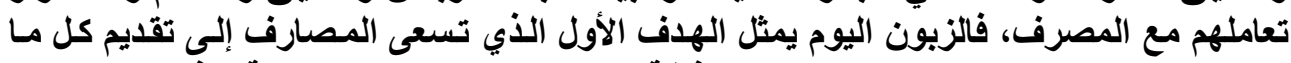

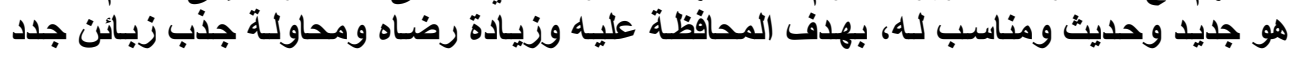

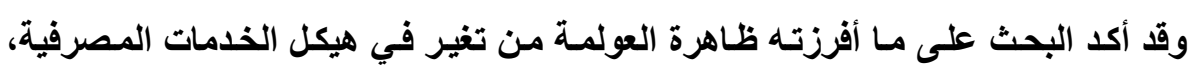

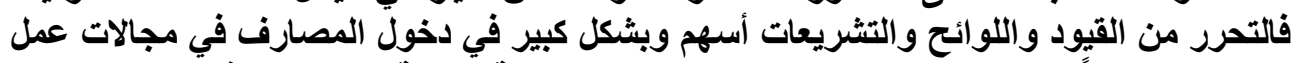

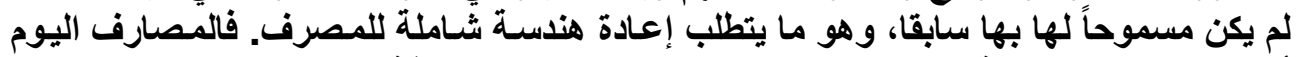

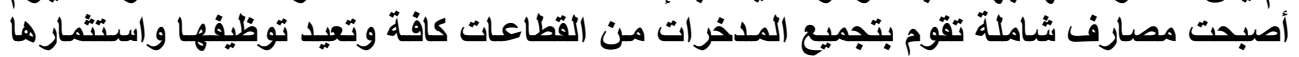

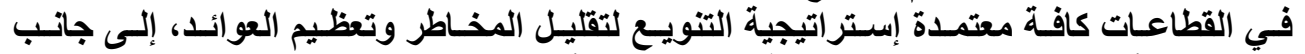

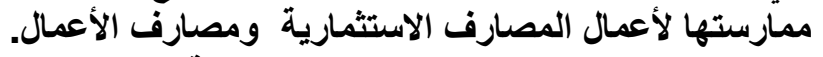

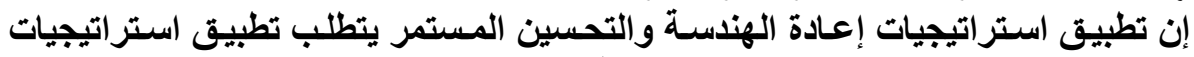

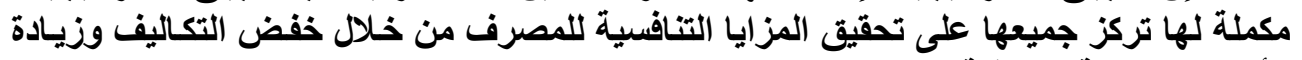

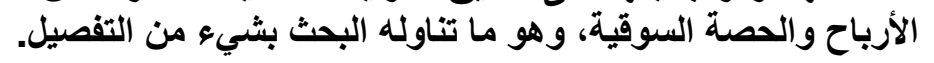

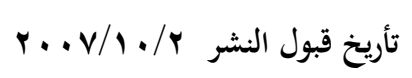




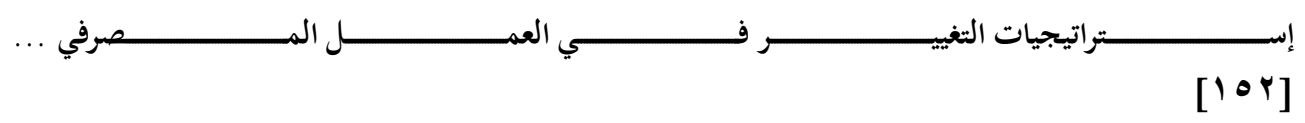

\title{
Strategies of Change in Banking: between Challenges of Globalization and Profession Requirements
}

\author{
Mowffaq A. Al - Saideyya (PhD) \\ Saja F. Mohammed \\ Assistant Professor \\ Assistant Lecturer \\ Department of Financial and Banking Sciences Department of Financial and Banking Sciences \\ University of Mosul \\ University of Mosul
}

\begin{abstract}
Banking is one of the most prominent activities that have been activated with International Developments, especially in both financial and economic aspects. Therefore, banks should be modified and incorporated with the developments through adopting many essential strategies that may help in continuing, competing and facing several challenges. Since globalization is one of most potential phenomena occurred in the financial activity, the research has shed light on reviewing globalization and other important challenges that banks may face and the requirements to be taken to incorporate with this phenomenon. First, banks should increase their capitals according to Basle committee requirements which are suitable for real risks that banks facing nowadays also technological development in information systems is one of challenges that lead to make change in financial business styles in order to decrease costs and obtain fastness and accuracy in the operations processes and fulfilling demands of customers, in order to achieve satisfaction and continue with their dealing with the bank. Customer nowadays is the first aim of banks in order to provide him with every modern and suitable to keep him dealing; increase his satisfaction and trying to seek for new customers. The research assured the exchange caused by globalization in the financial services structure. Liberation from conditions, regulations and legislation led the banks greatly to enter business aspects that have not been permitted before. Banks today became universal banks ones, they collect savings from all sectors and re - invest them in all sectors depending on varying strategy to decrease risks and enlarge returns in addition to practice investing banks business and banks that need a whole re - engineering for banks. Applying strategies of re engineering and continues improvement demand applying concentration on getting competitive features for bank through decreasing costs, increasing returns and market portion, which the research adopted in details.
\end{abstract}

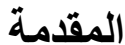

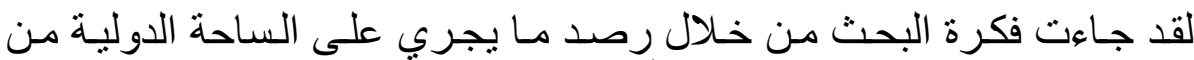

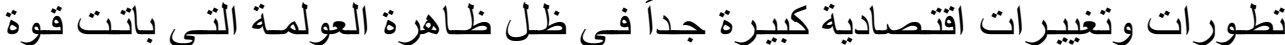

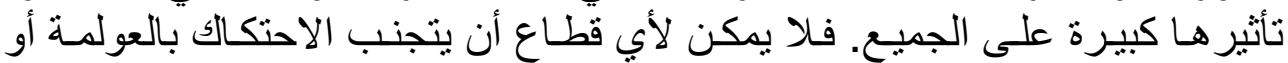

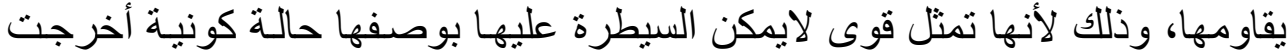

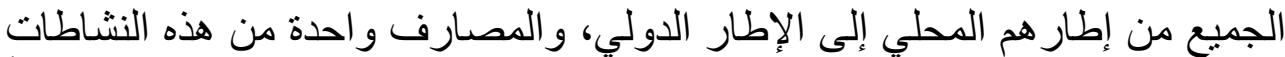

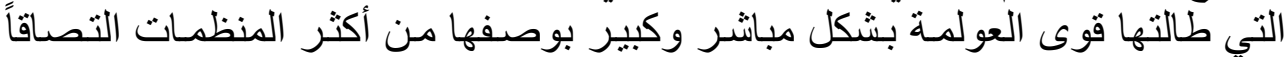

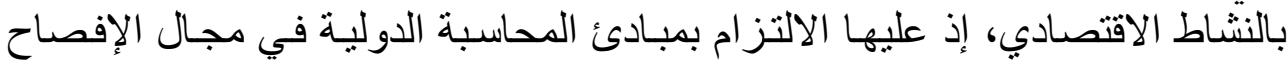

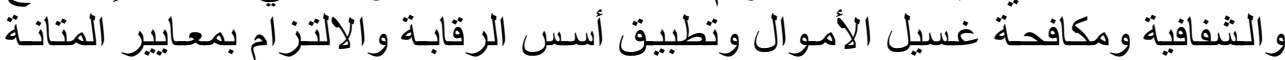

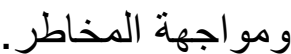


عليه فقد أصبحت المصارف اليوم تنظر إلى العولمة على أنها قوى تأثير

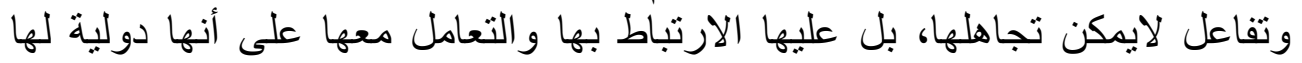
آلياتها وتقنياتها المادية و الحسية تهاعية علية

يمكن تحديد أهمية البحث من خلال تتبيه الإدارة المصرفية ولاسيما في منهجية البحث أهمية البحث

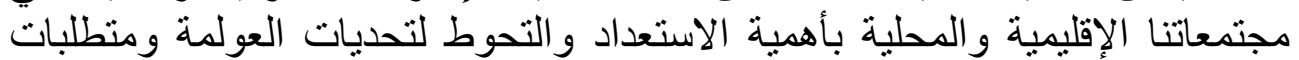

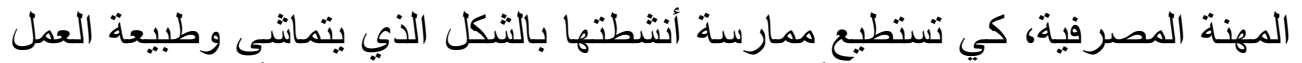

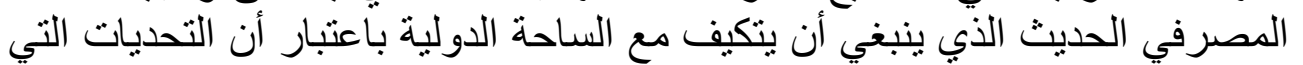
تواجه نشاط المصرف خلقت متطلبات ينبغي على المصارف الأخذ بها بوصفها متطلبات مهنية

مشكلة البحث

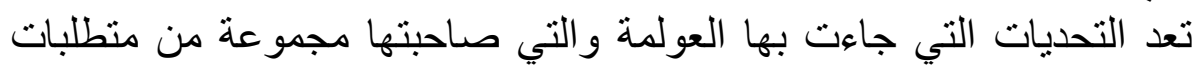

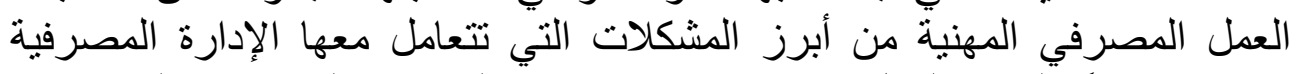

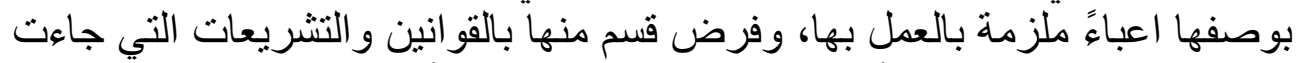

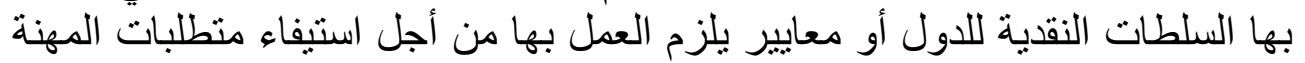

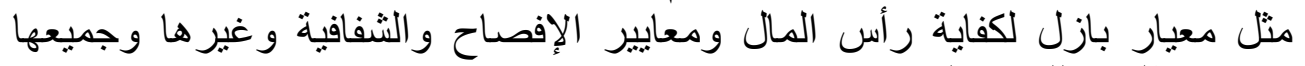
باتت متطلبات للمهنة المصرفية.

يهدف البحث إلى تحديد طبيعة التغيير ات التي يستوجب على الإدارة المصرفية

$$
\text { هدف البحث }
$$

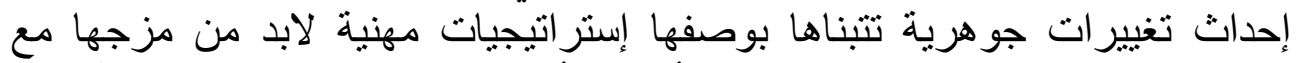

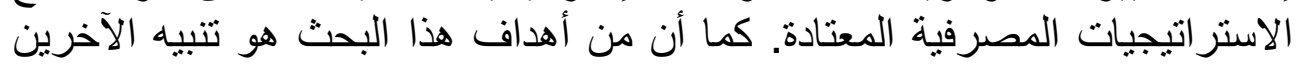

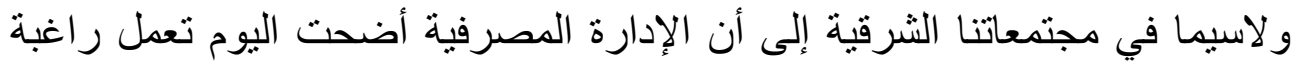

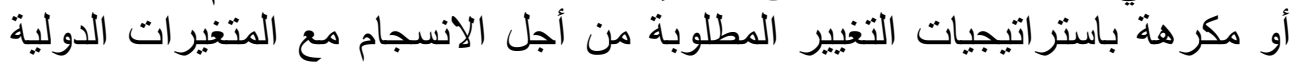
التي بات الجميع يطلق عليها (ظاهرة العولمة).

يمكن بناء فرضية أساسية للبحث انطلاقاً من مشكلة البحث التي تحاول الإجابة

\section{فرضية البحث}

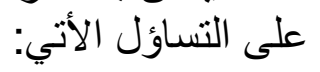
كيف يمكن للمصارف أن تواجه تحديات العولمة، وتلتزم بمتطلبات المهنة المصرفية ؟

ولإججابة على هذا التساؤل يمكن التحقق من الفرضبة الآتية:

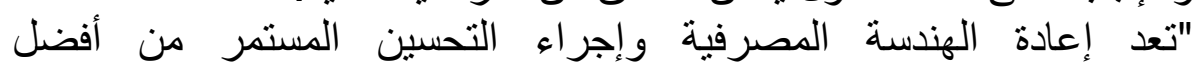
الاستر اتيجيات لمو اجهة تحديات العمل المصرفي ومتطلباته المهنية". 


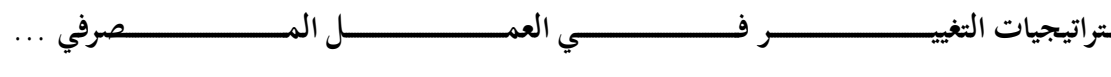

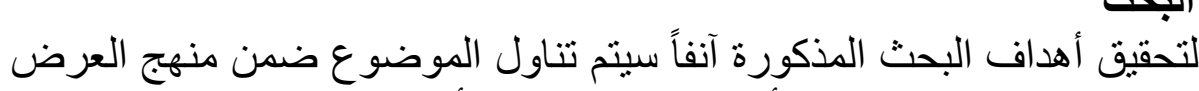
منهج البحث

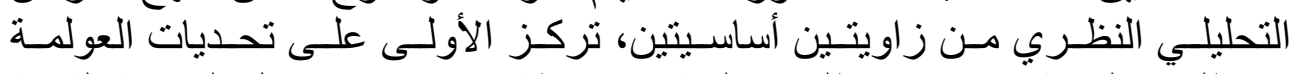

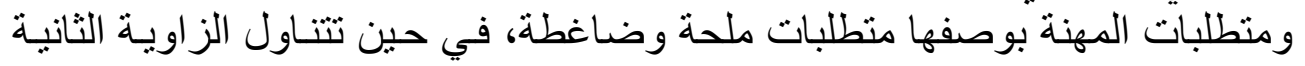

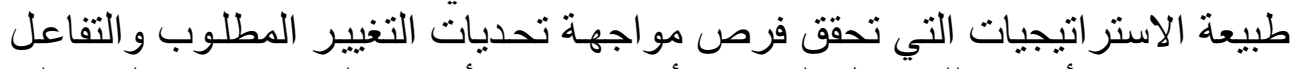

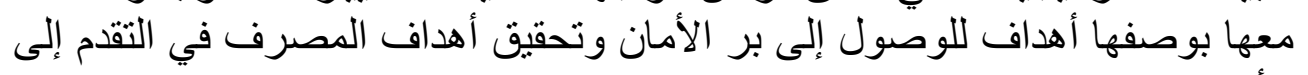

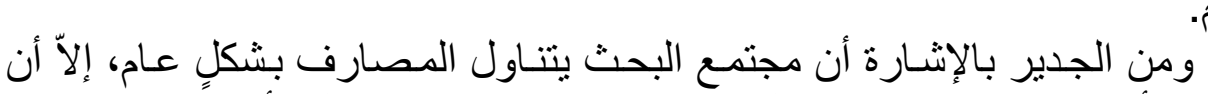
الأمام.

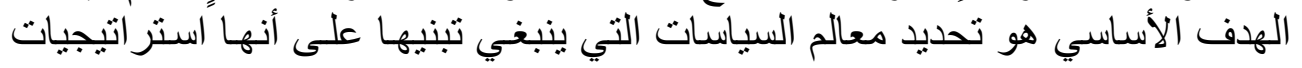
مصرفية لمصأر فنا المحلية والعربية معالم العبية.

العمل المصرفي بين تحديات العولمة ومتطلبات المهنة

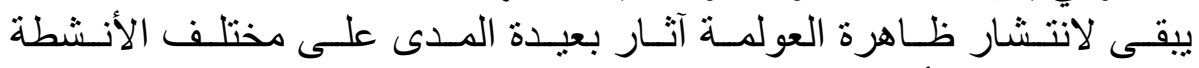

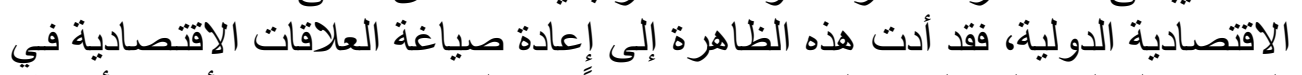

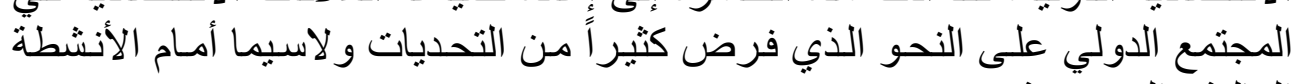
المالية و المصرفية الأية لقد تمثلت أهم ملامح تحديات العمل المصرفي في الاتجاه المثز ايد نحو التحرر

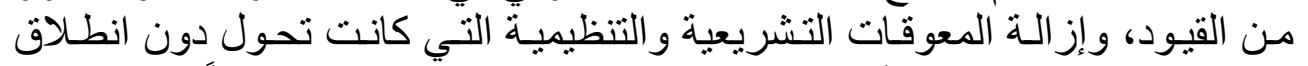

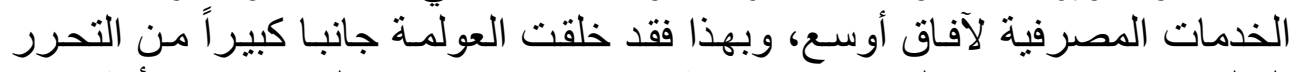

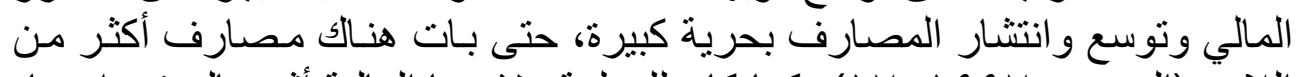

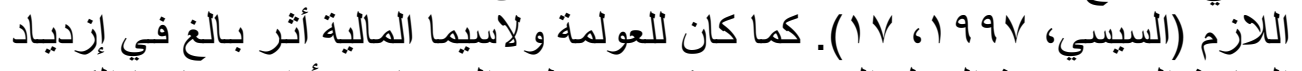

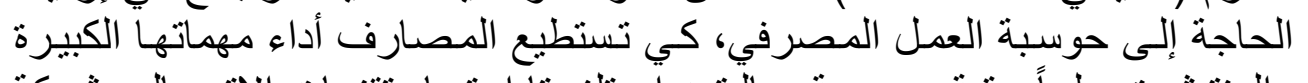

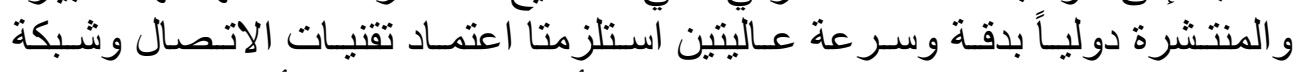

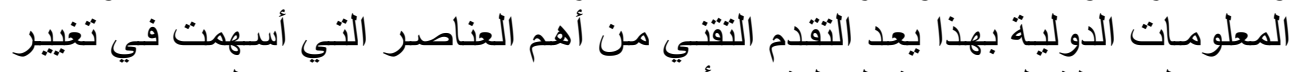

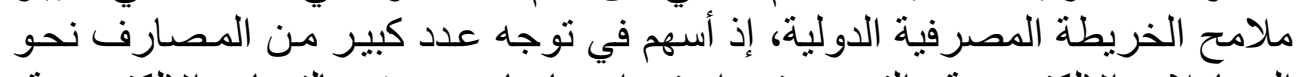

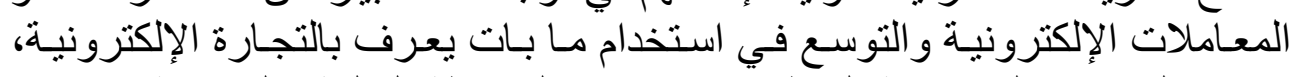

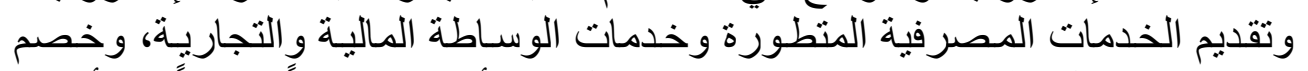

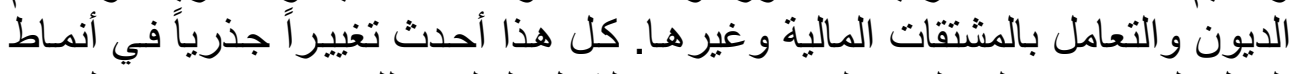

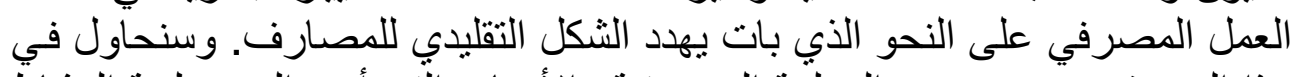

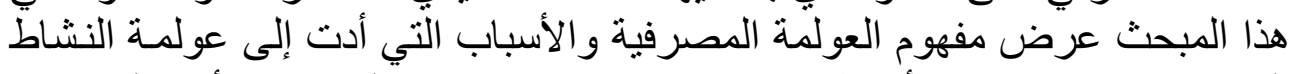

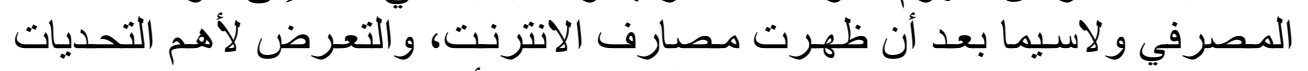

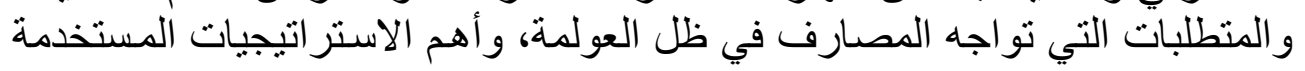
لمو اجنتها. 


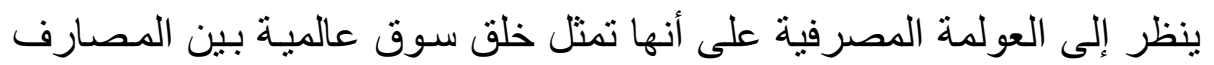

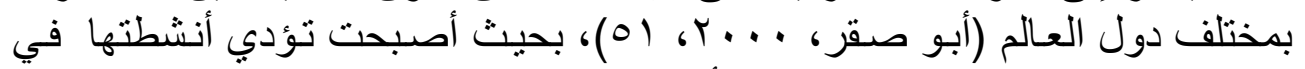

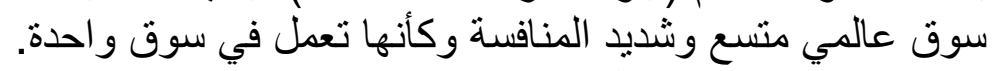

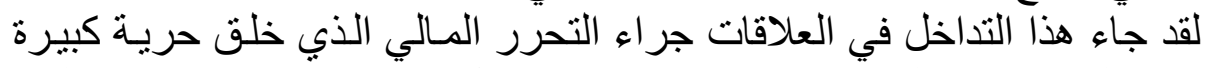

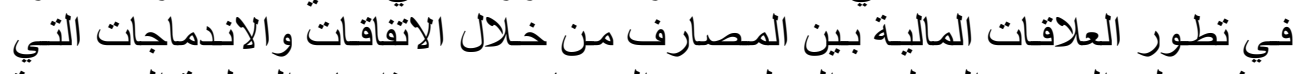

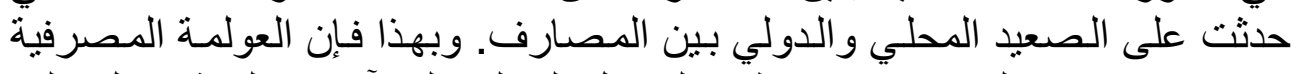

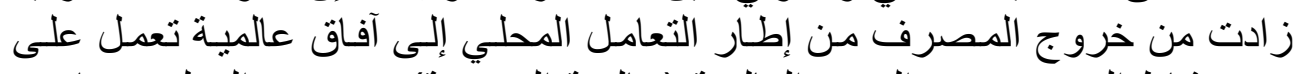

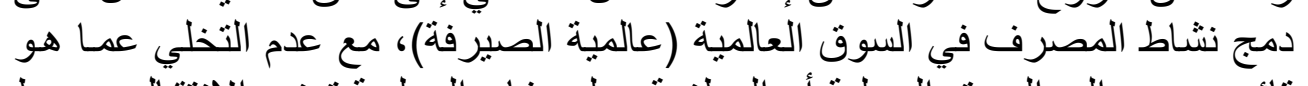

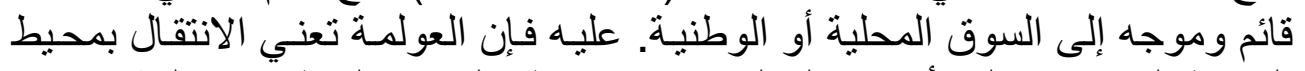

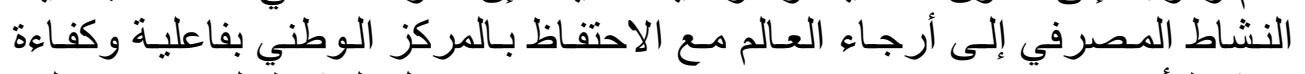

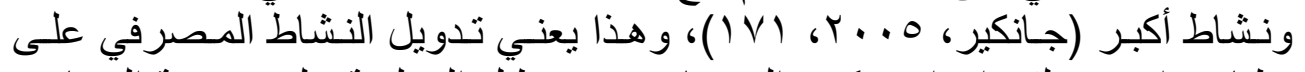

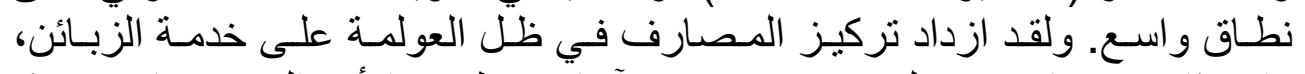

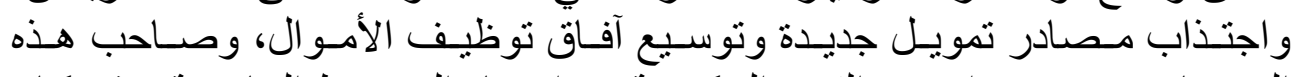

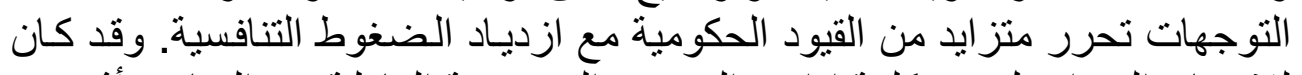

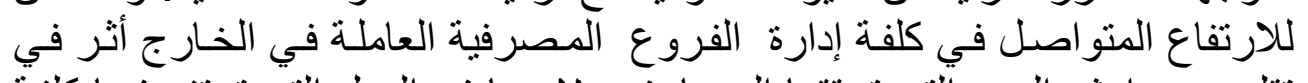

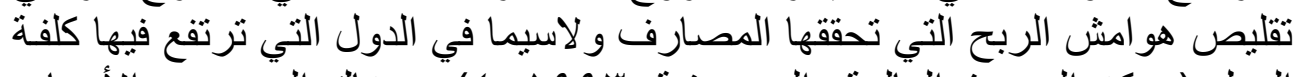

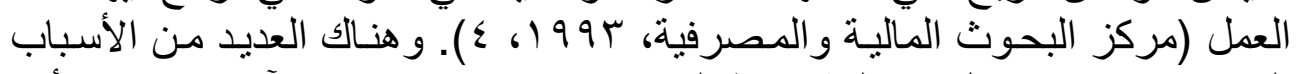

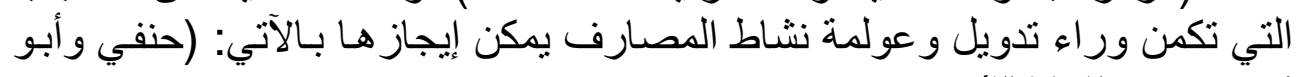

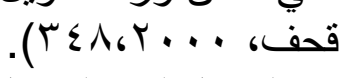

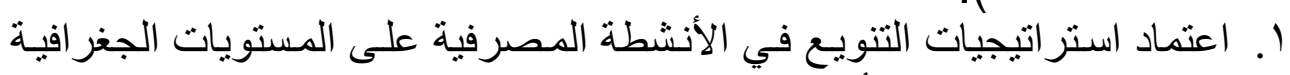

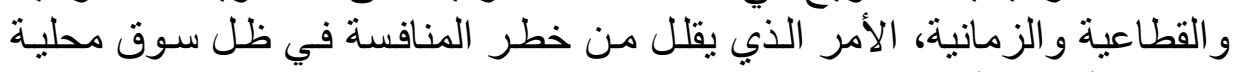
متخمة بالخدمة المصرفة والزية.

r. r. التوسع الكبير في استخدام تقانة الخدمات المصدرفية (الصيرفة الإلكترونية).

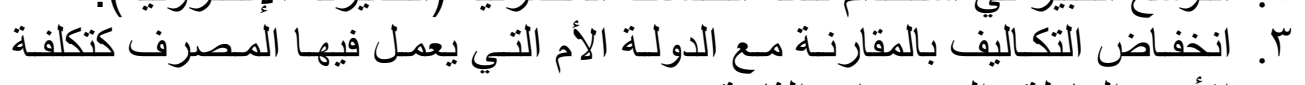

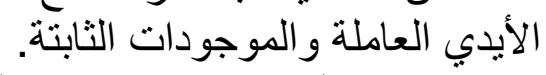

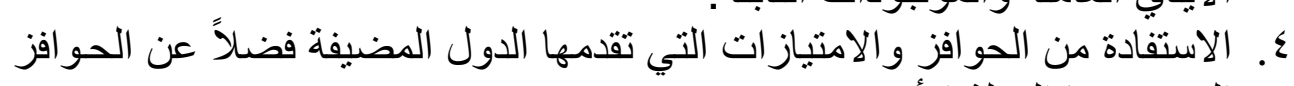
التي تقدمها الدولة الأمن التون. •. الرغبـة في التوسـع والنمـو والانتشـار الـدولي مـن أجل تحقيـق أهداف المـالكين

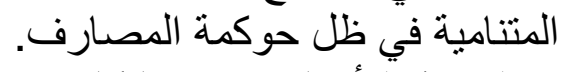

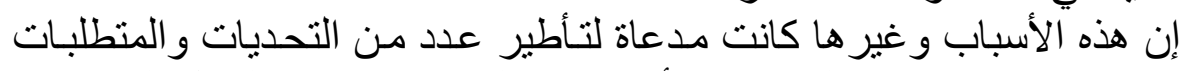

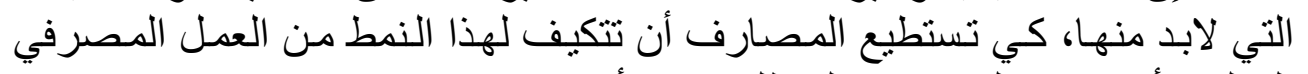
الدولي وأبرز هذه التّحديات و المنطلبات ما يأني:

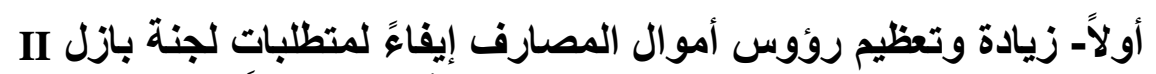

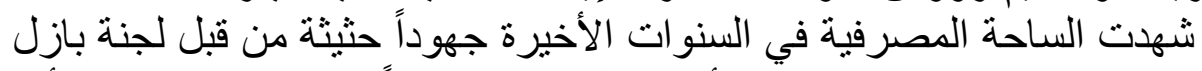

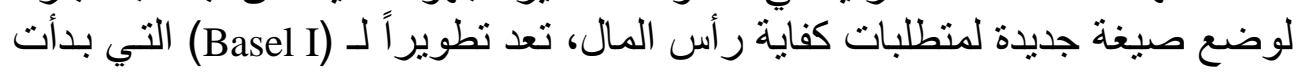


عام 9^^19 و والمعروفة بـ (Basel II)، ولقد شكل هذا الأمر تحدياً مهماً أمسام الصناعة

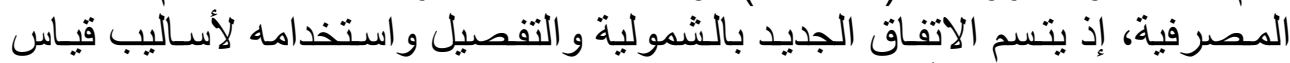

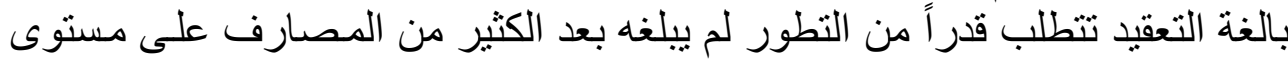

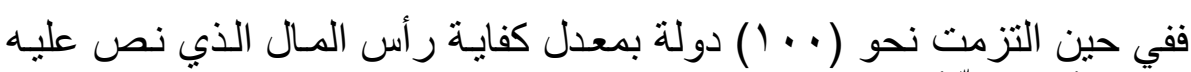
العالم.

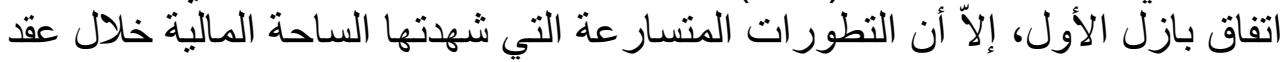
التسعينيات من القرن الماضي ومطلع هذا القرن قد قلصت من فاعليته بوصفه التانه وسيلة

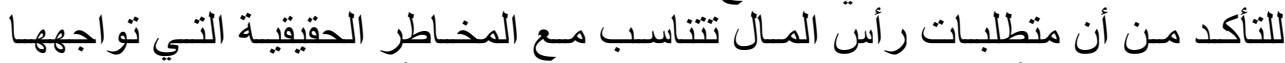

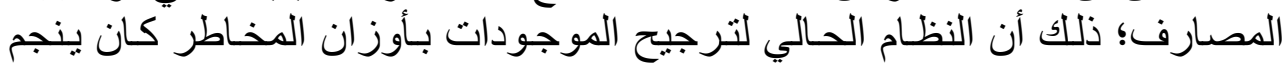

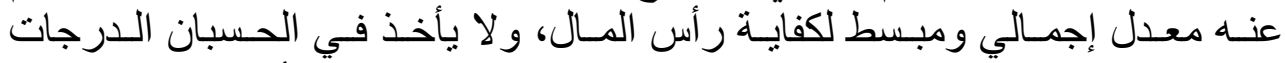

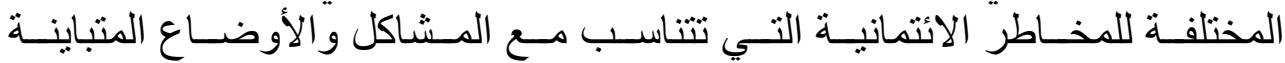

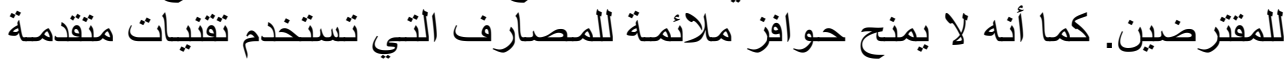

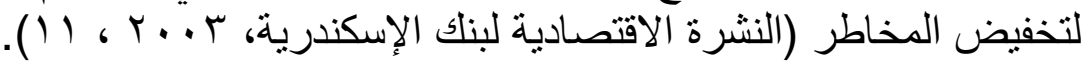

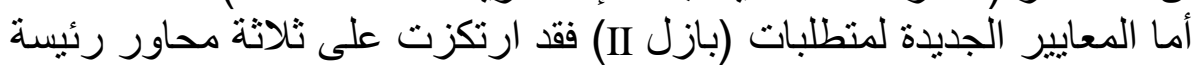

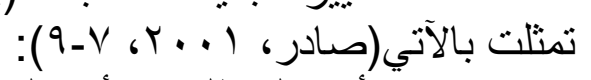

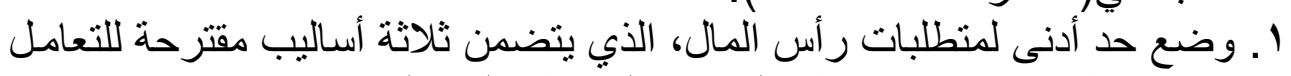
مع مخاطر الائتمان ومخاطر السوق والمان المخاطر التشغيلية هي:

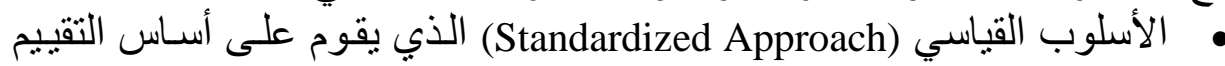

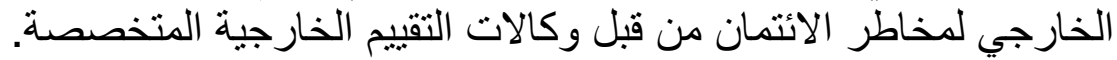

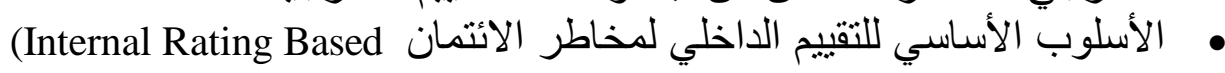
.Approach (IRB)) (Advanced Internal • الأسـوب المتقدم للتقيم الداخلي لمخـاطر الائتمـان) .Rating Based Approach (AIRB) Y (Supervisory Review of Capital المر اجعـة الرقابيـة لكفايـة رأس المـال .Adequacy)

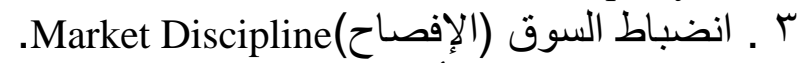

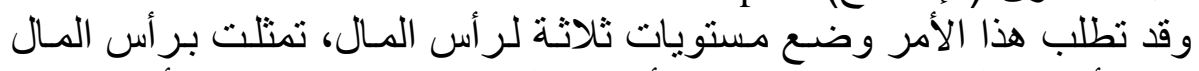

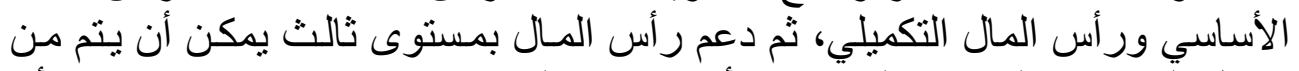

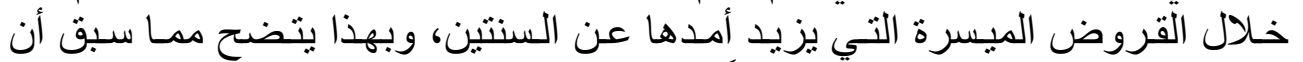
(بازل) (II)

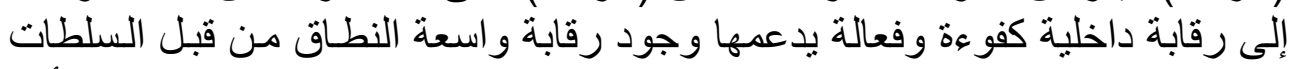

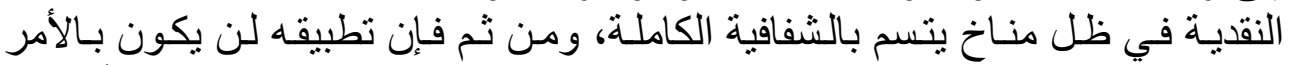

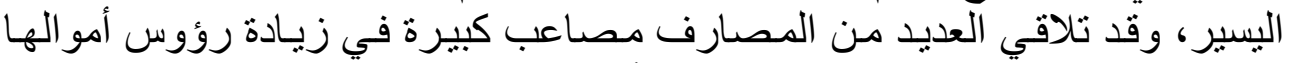

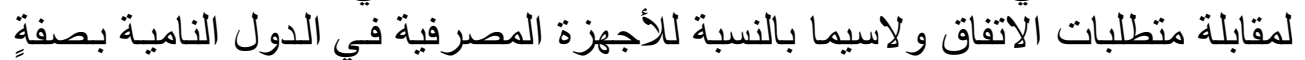
عامة و الدول العربية بصفةٍ خاصة. لاصنة 
Technological Revolution أنانياً الثورة التكنولوجية

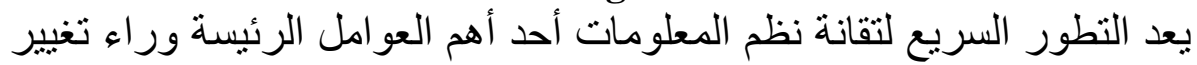

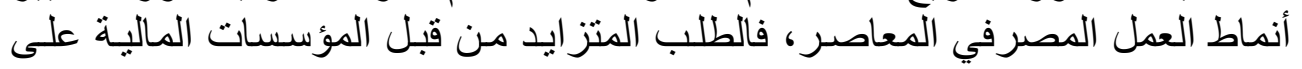

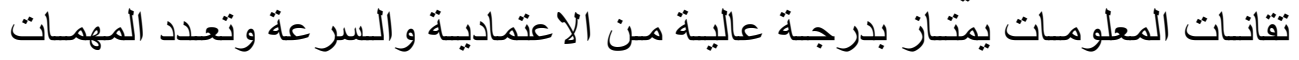

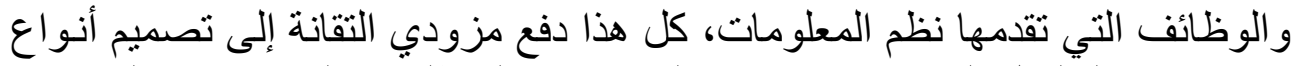

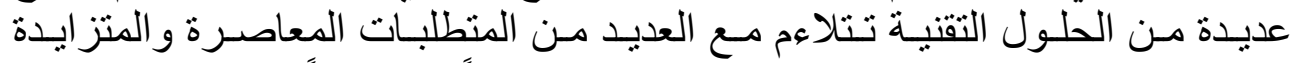

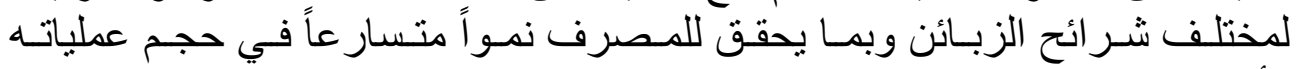

و على الرغم من الفوائد العديدة التي تقدمها تقانـة المعلومـات الحديثة، إلاّ أنها

$$
\text { وأرباحه. }
$$

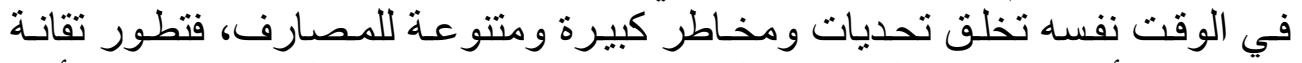

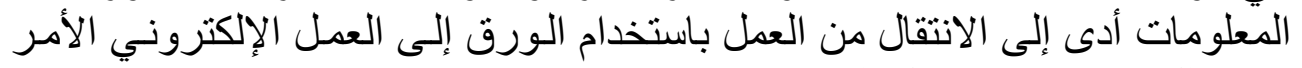

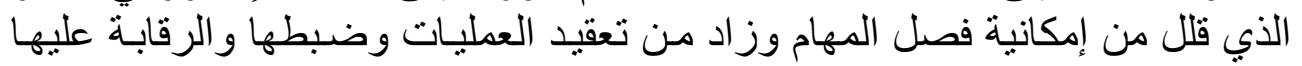

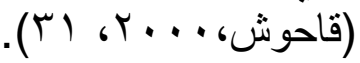

كما باتت الخدمات المصرفية الماته المقدمة عبر القنوات الإلكترونيـة المختلفة تهدد

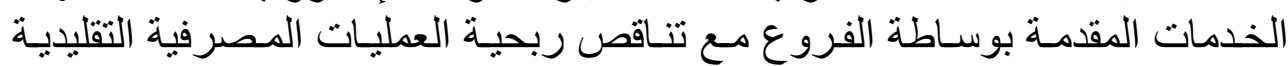

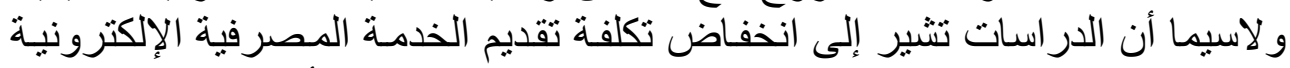

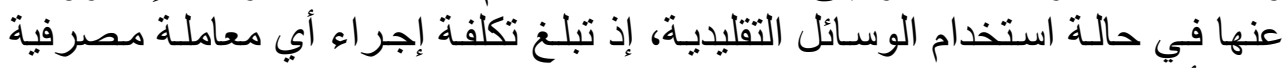

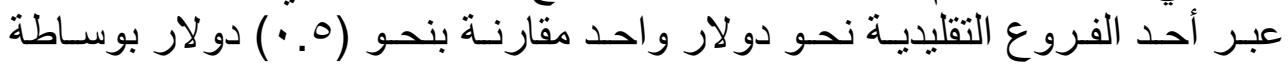

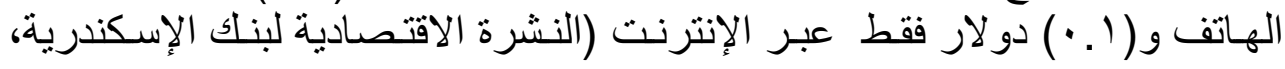

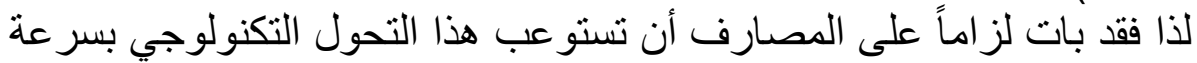

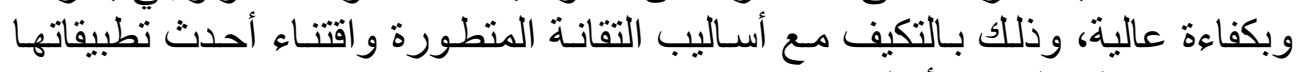

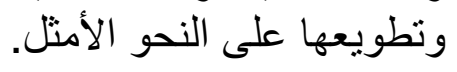

\section{ثالثاً. تغير نمط وأطر الخدمات المصرفية}

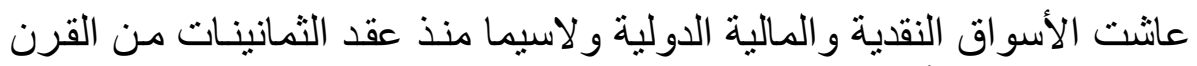

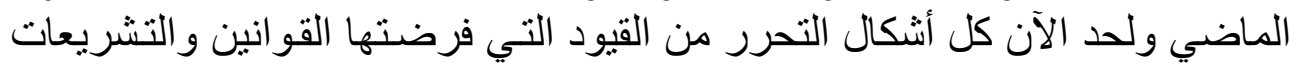

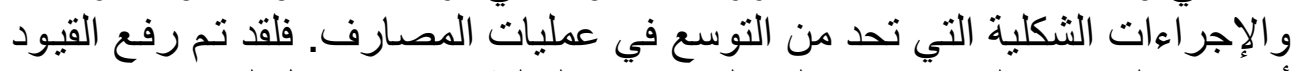

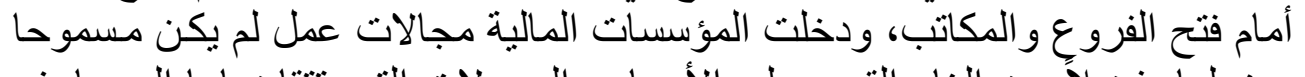

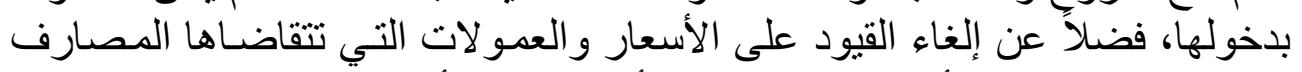

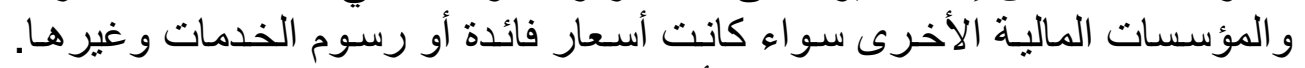

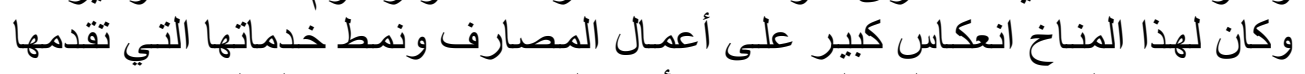

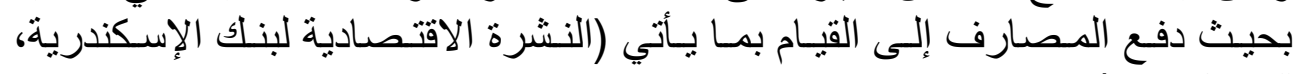
:) (10 r. r. r

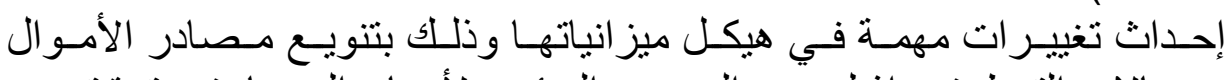

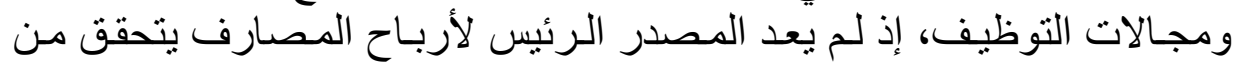




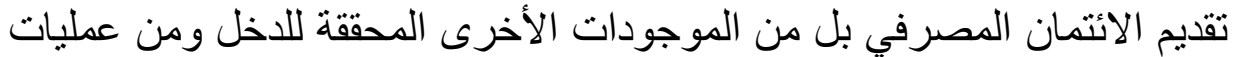

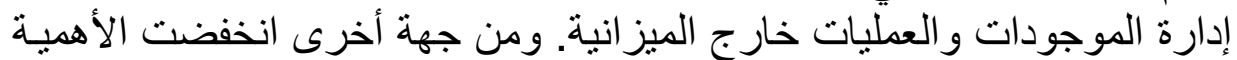

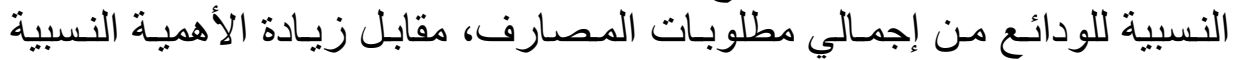

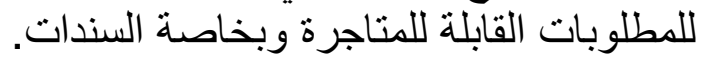

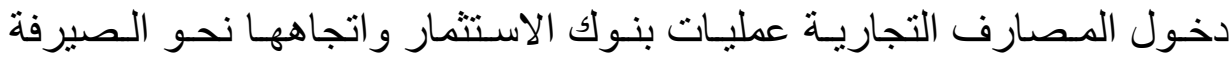

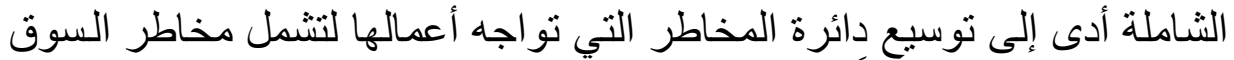

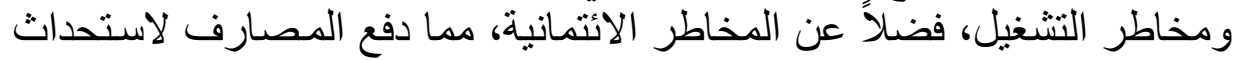

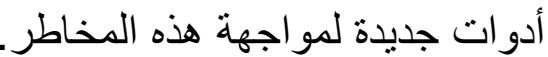

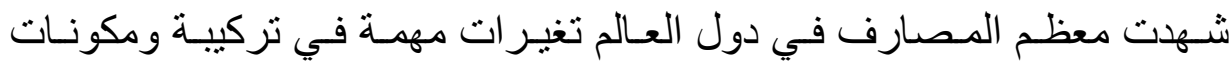

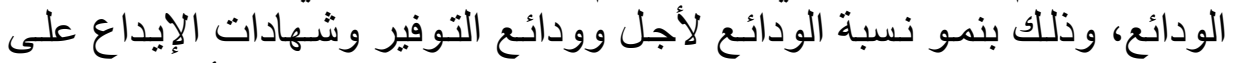

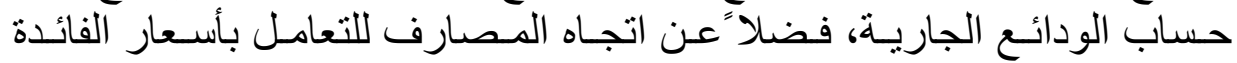

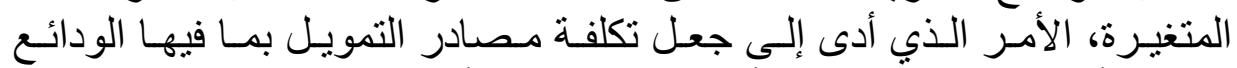

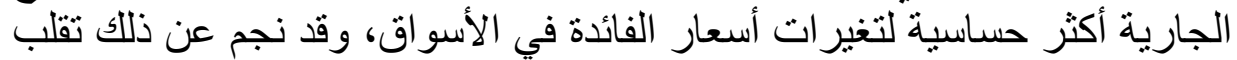

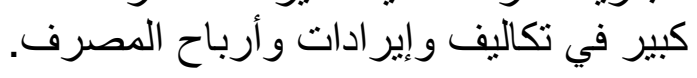

رابعاً عولمة الخدمات المالية

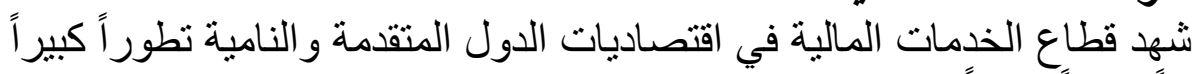

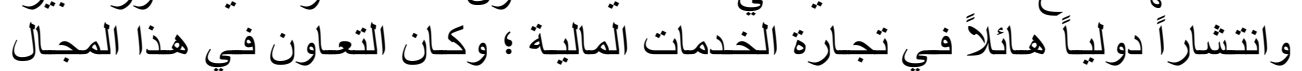

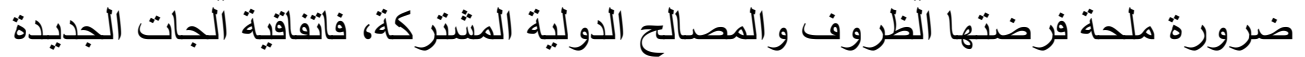

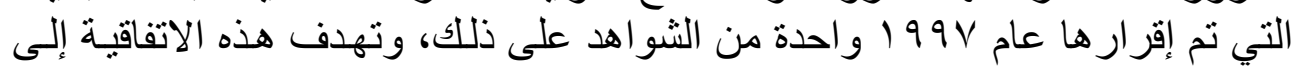

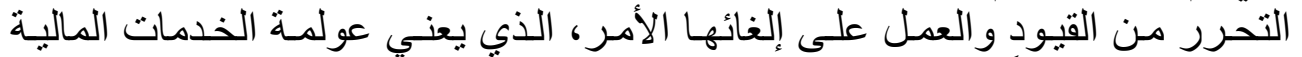

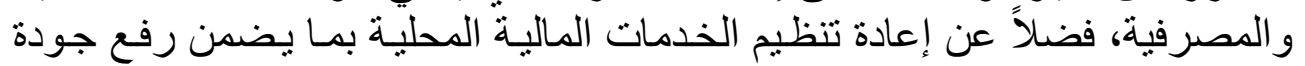

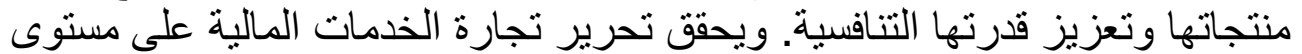

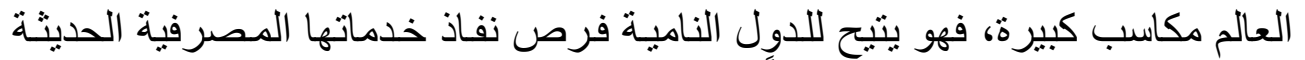

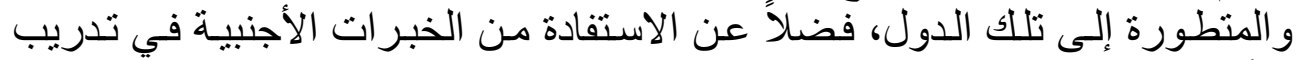

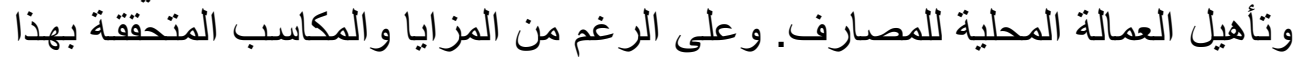

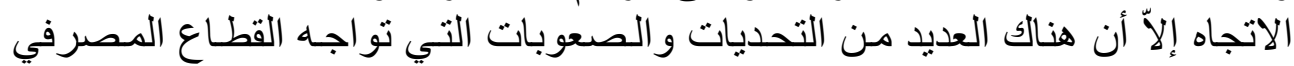

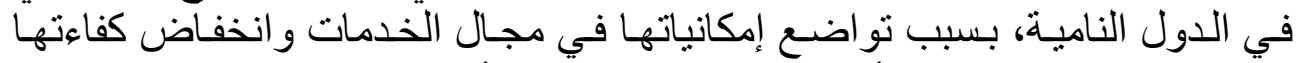

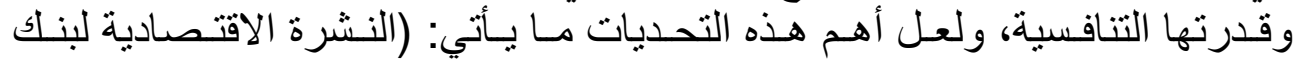

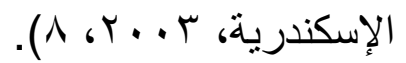

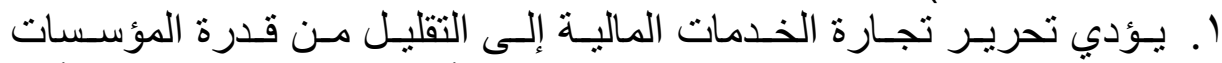

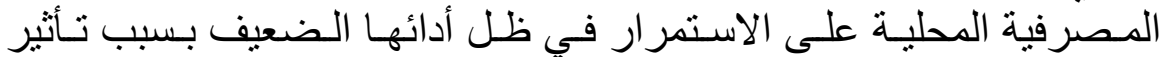

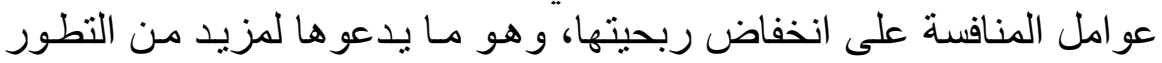

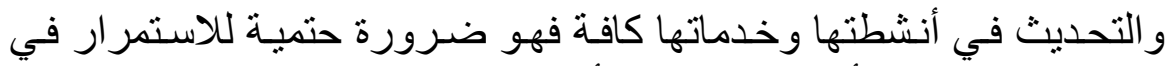
الساحة المصرفية الأمر الذي يحملها أعباء كبيرة قد لا تتمكن من تغطيتها. 


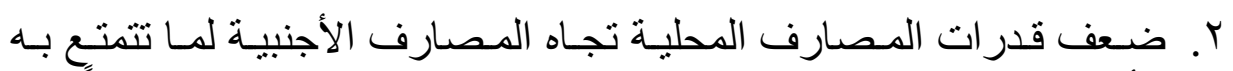

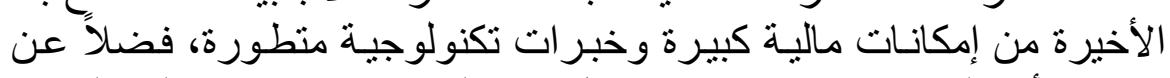

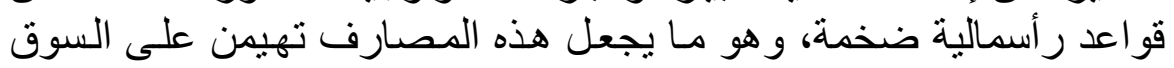
المحلي.

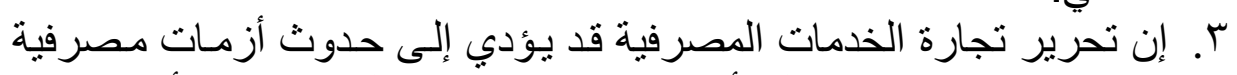

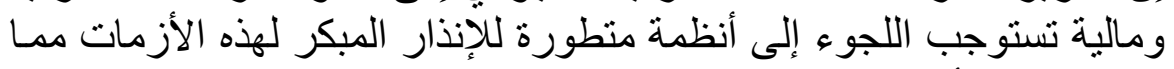
يعني تكاليف أضافية.

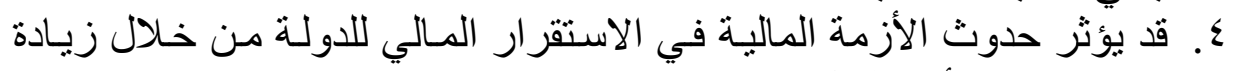

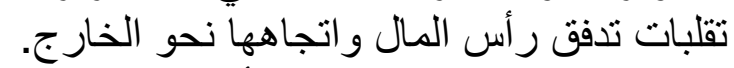

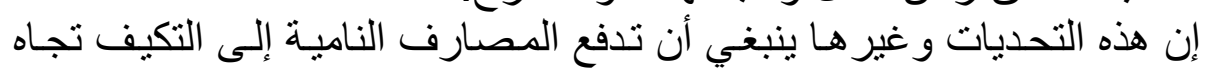

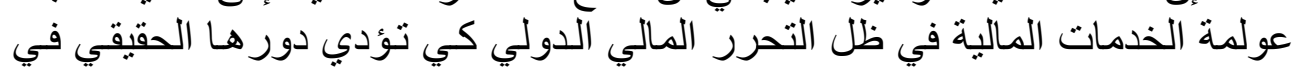

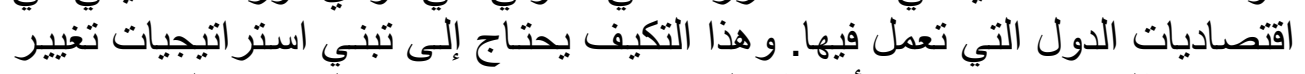

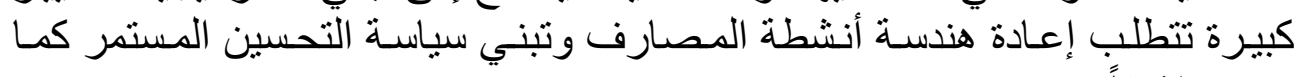
سنرى لاحقاً.

\section{خامساً- الاندماج المصرفي}

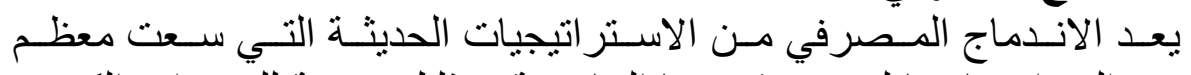

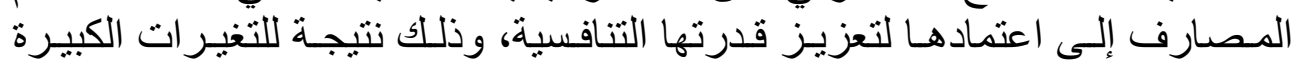

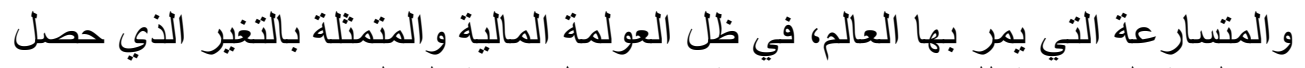

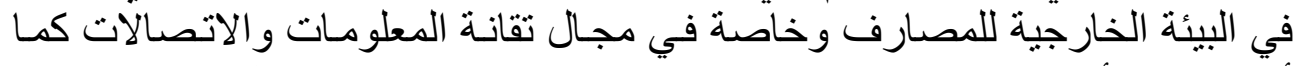

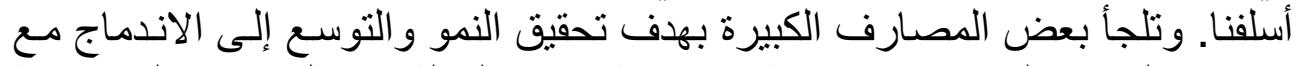

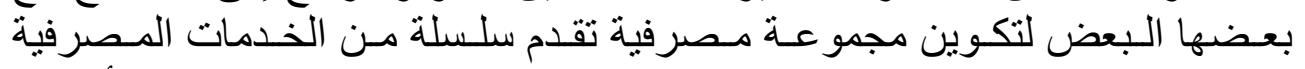

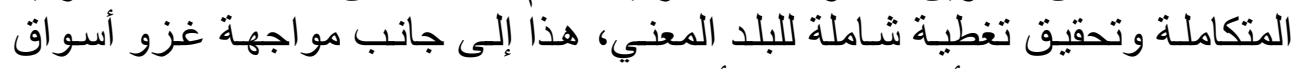

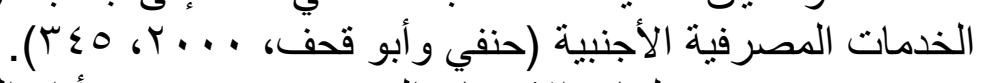

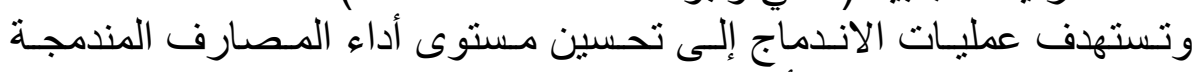

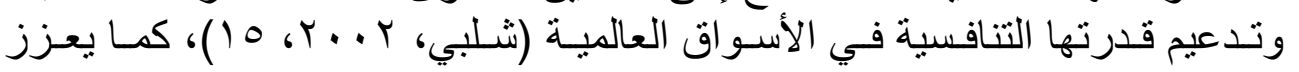

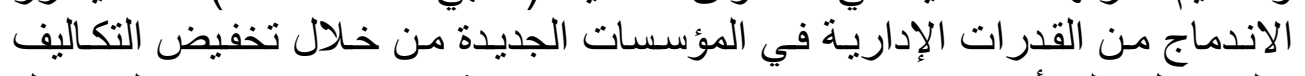

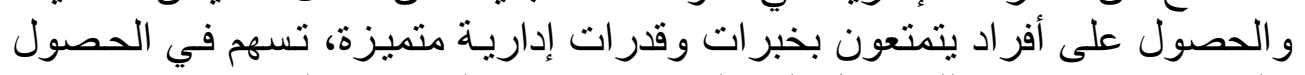

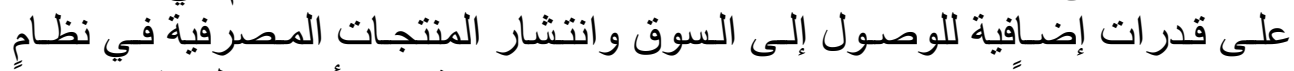

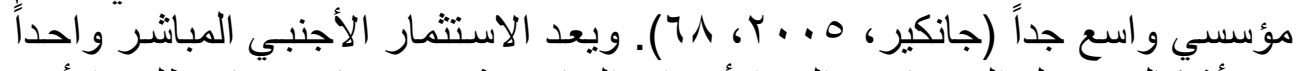

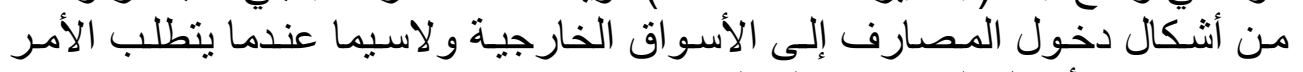
زيادة رؤوس أمو ال المصار فول المدارف المحلية.

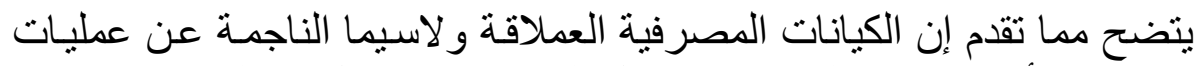

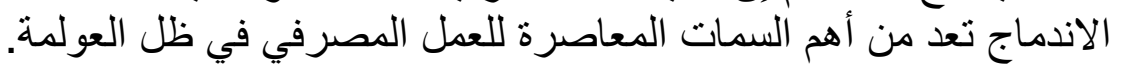

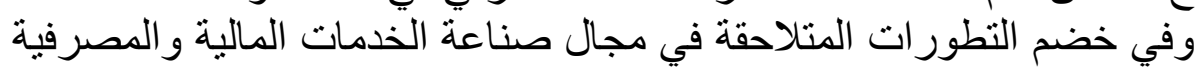

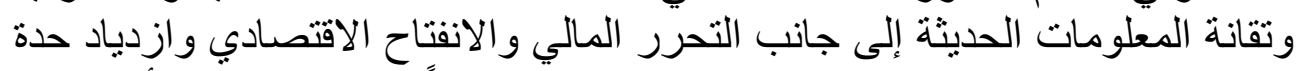

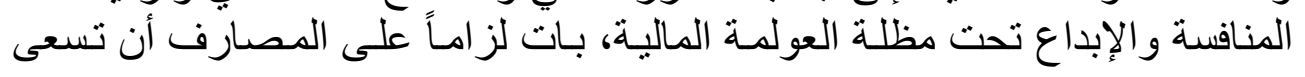




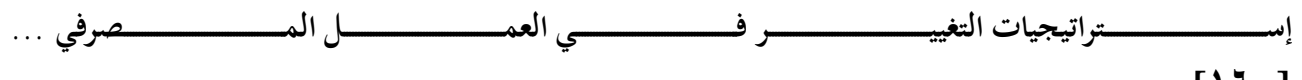

وبخطو ات متسار عة نحو تبني استر اتيجيات فاعلة للارتقاء بمستوى أدائها وخدماتها

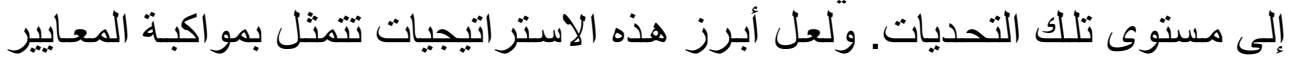

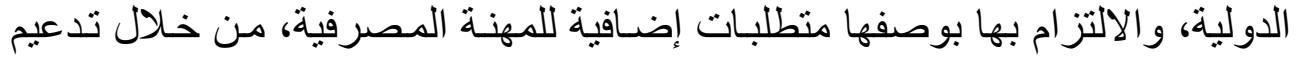

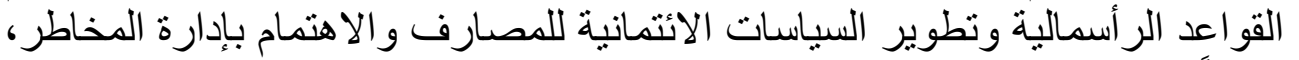

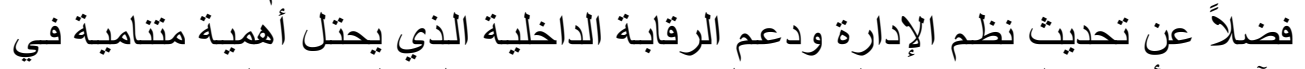

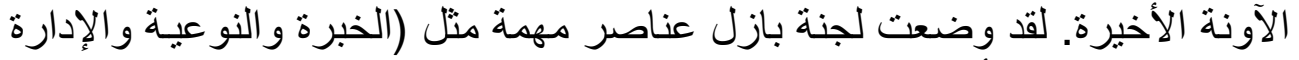

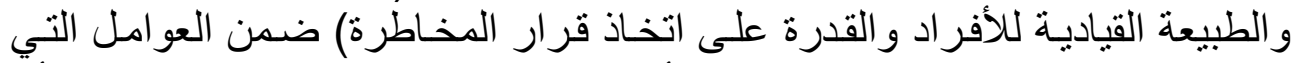

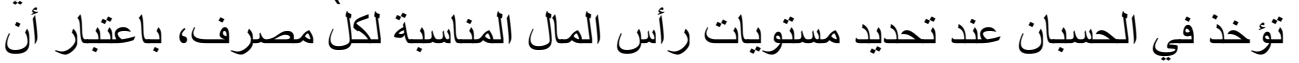

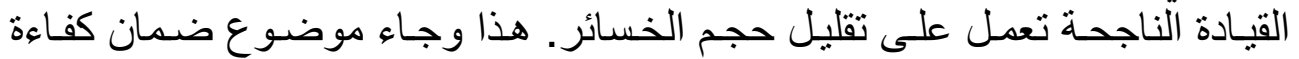

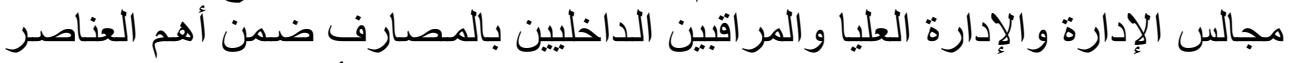

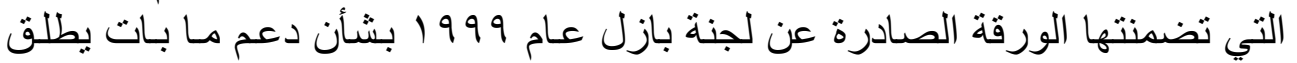

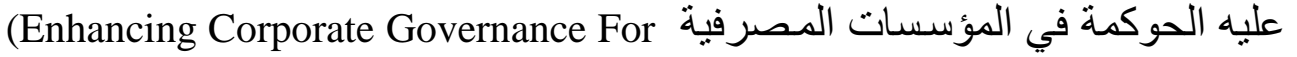
Banking Organization)

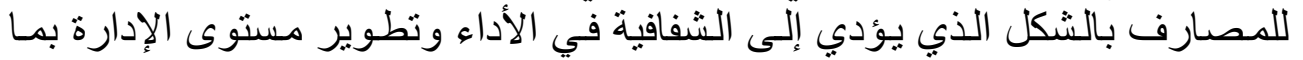

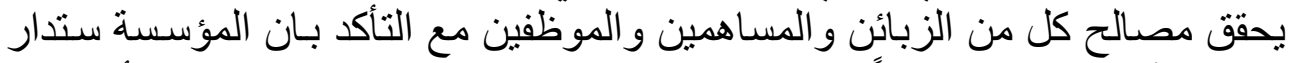

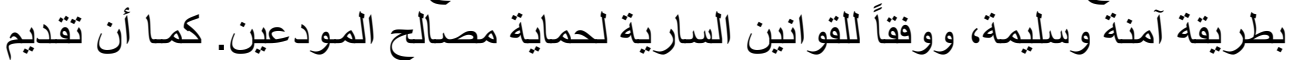

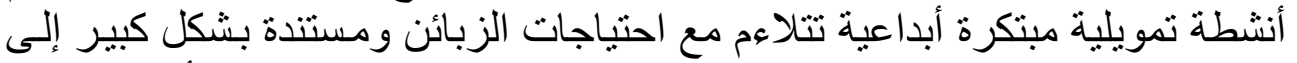

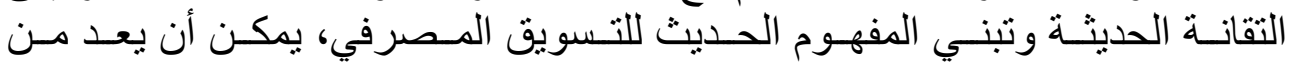

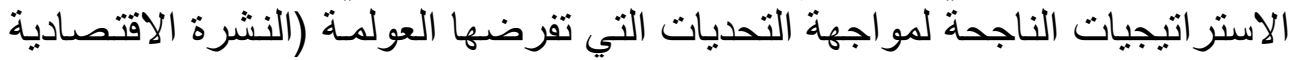

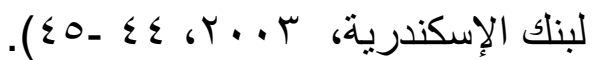
نخلص مما سبق أن على المصارف أن أن تتبنى استر اتيجيات التغيير و التكيّف

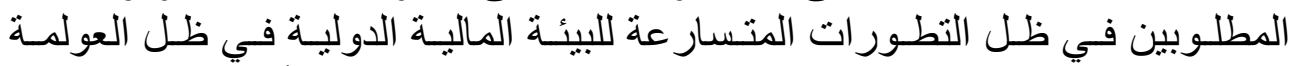

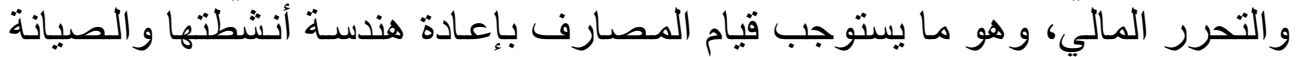

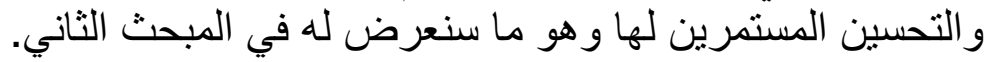

إعادة الهندسة والتحسين المستمر: المفهوم والاستراتيجيات

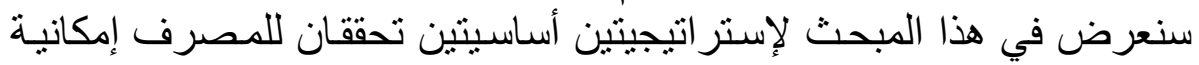

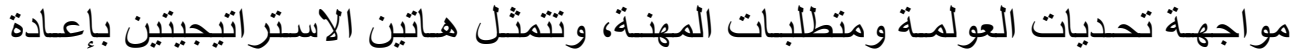

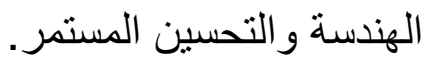
أولاًا إعادة الهندسة

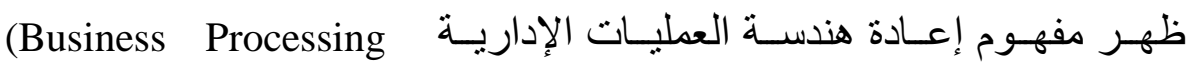
Re-engineering (BPR))

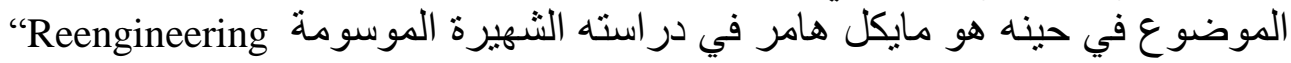
Work : Don’t Automate Obliterate”

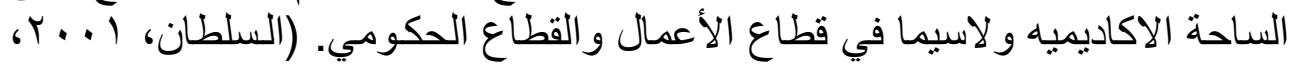




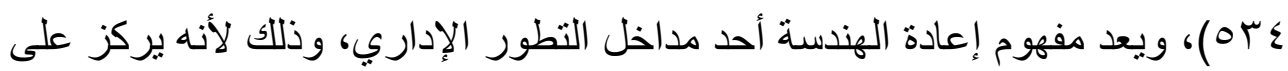

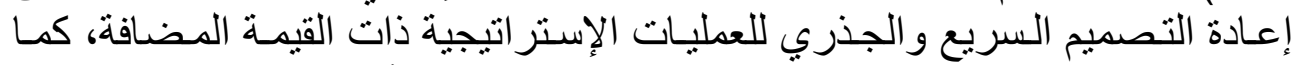

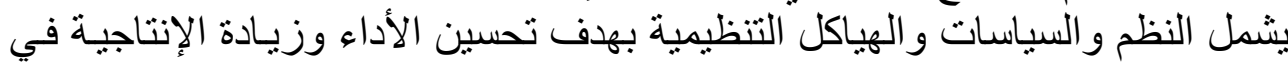

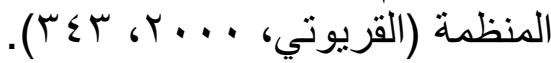

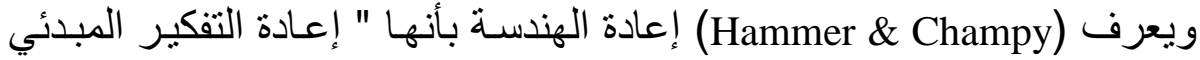

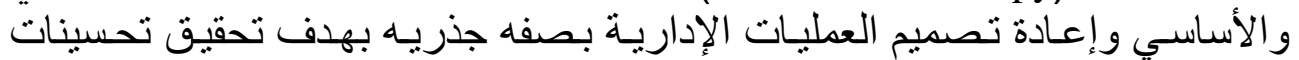

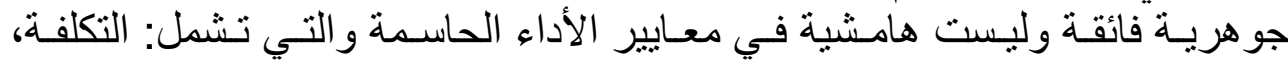

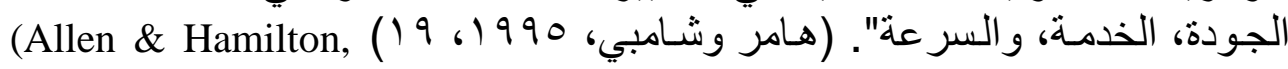
2000,12 )

وبهذا يمكن عد الهندسة أساساً لتحقيق متطلبـات إدارة الجودة الشاملة بوصفها

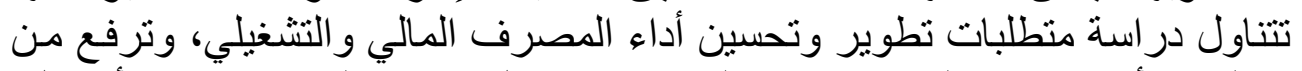

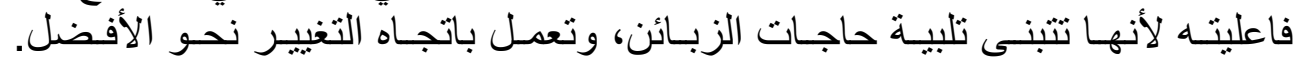

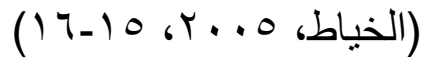
ويحقق تطبيق إعادة الهندسة عدداً من الأهداف التي تعود على التى التظبيم بكفـاءة

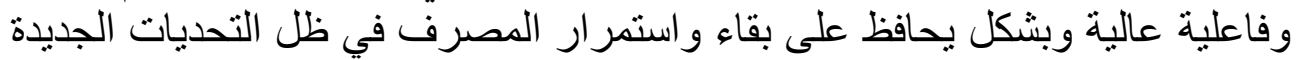

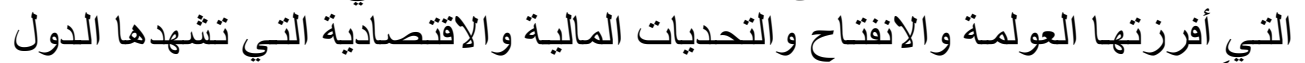

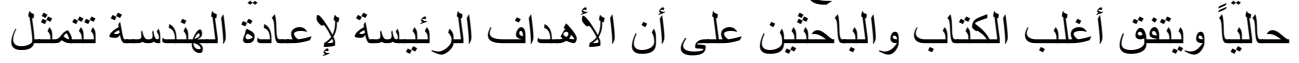

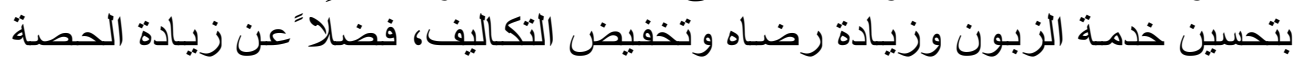

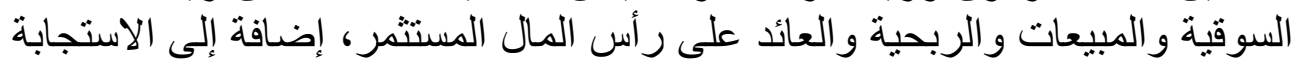

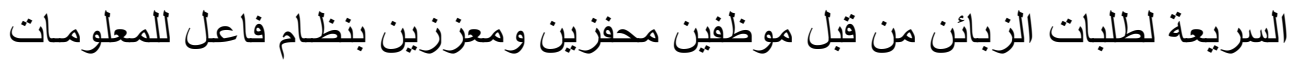

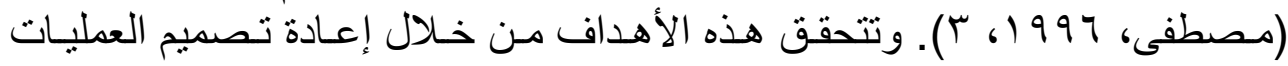

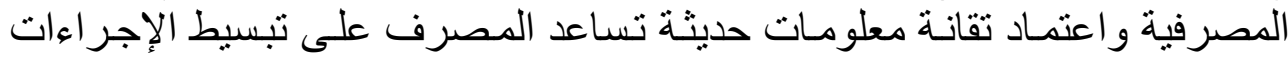

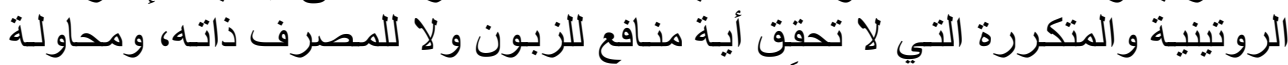

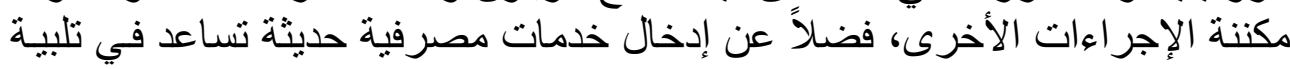

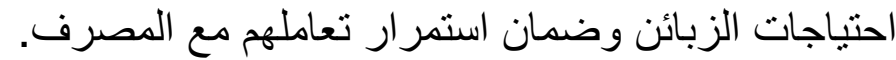

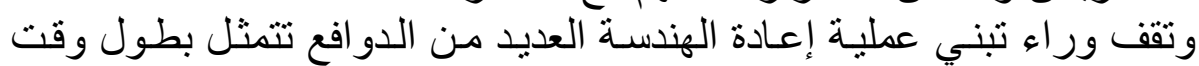

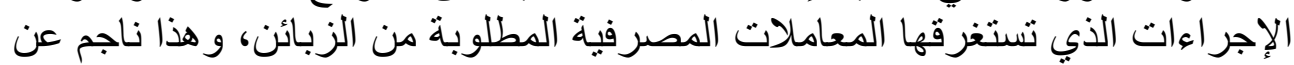

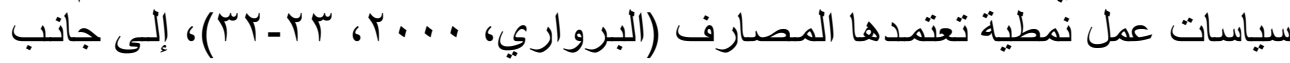

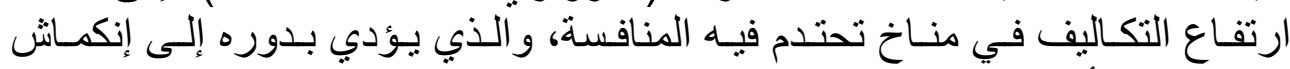

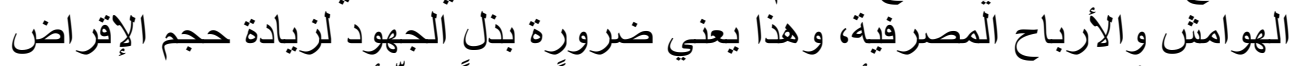

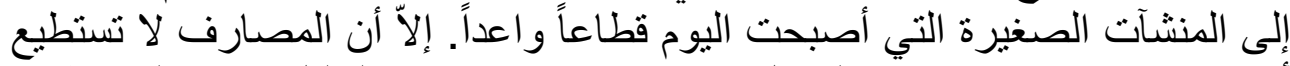

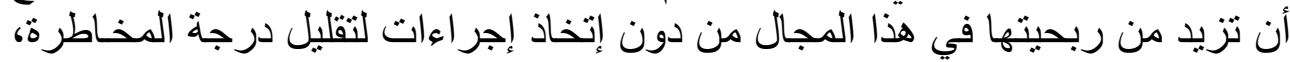

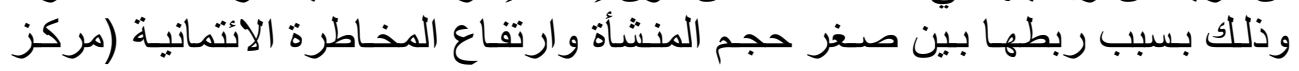

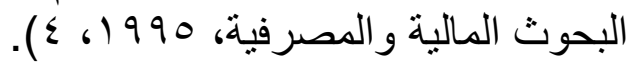




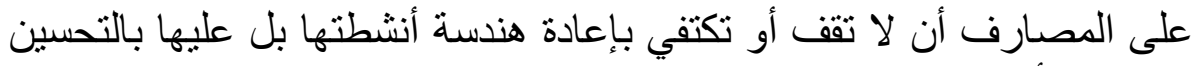

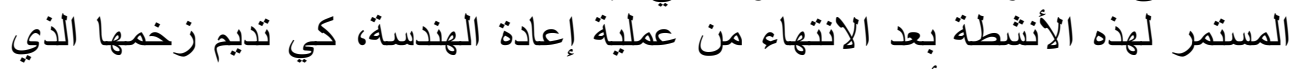

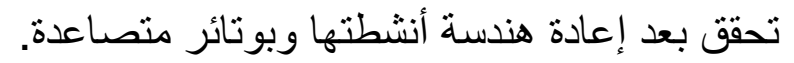

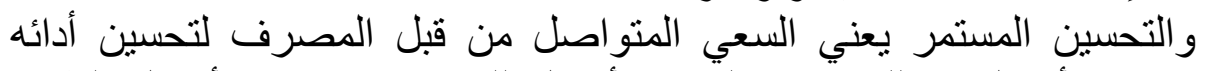

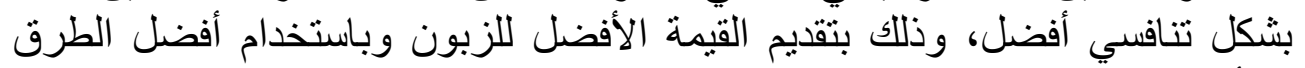

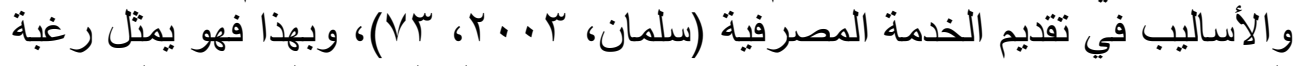

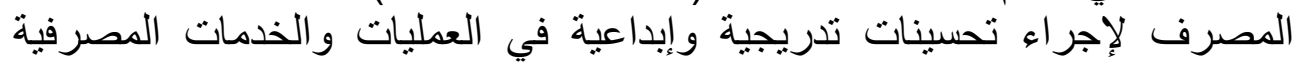

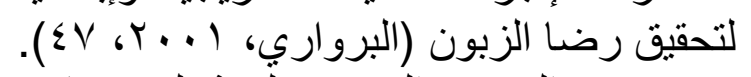

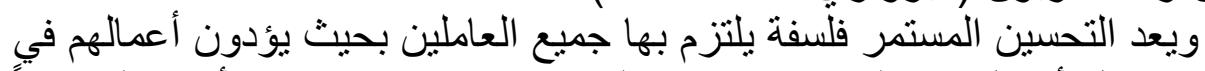

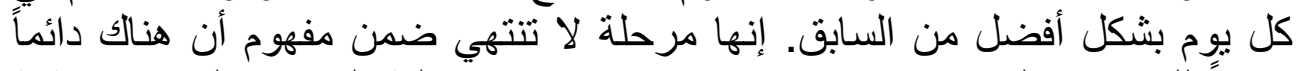

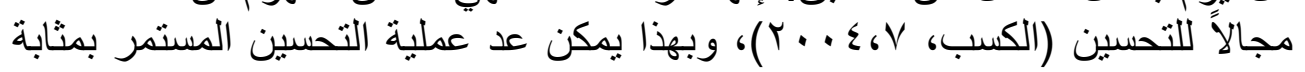
عملية صيانة لإعادة الهندسة.

ويحقق التحسين المستمر عدداً من الأهداف تتمثل بخفض تكان تكاليف تقديم الخدمة

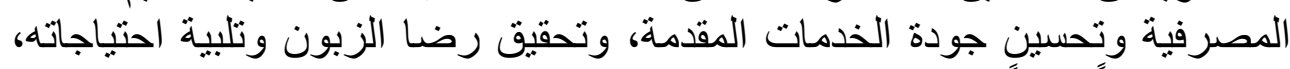

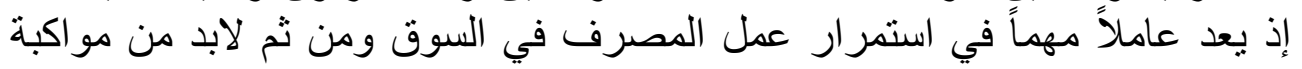

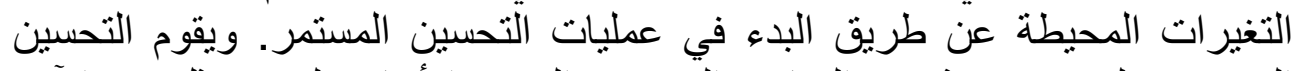

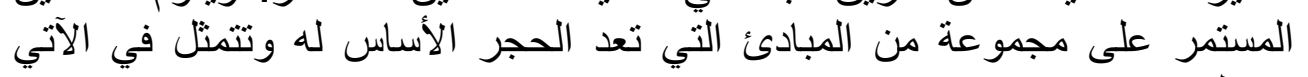

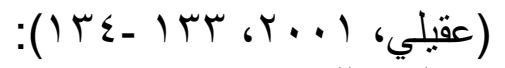
• ليس للتحسين نهاية فهو مستمر طالما أن المصرف قائم وهو من متطلبات وجوده وتطوره. التحسين عملية شاملة وتحتاج إلى جهود جميع العاملين في المصرف فهي عمل هماعي من مسؤولية الجميع.

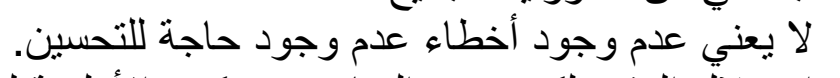

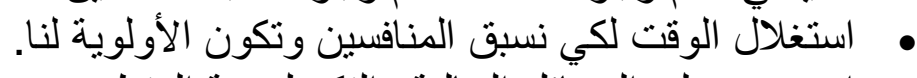

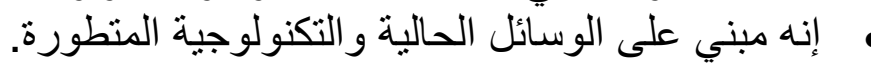

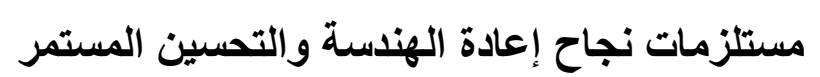

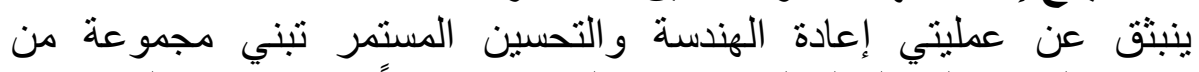

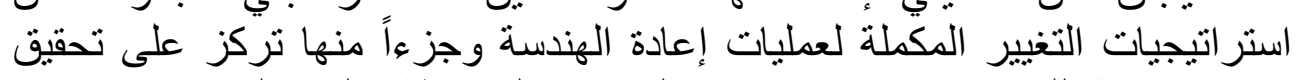

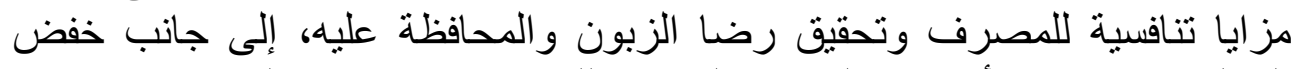

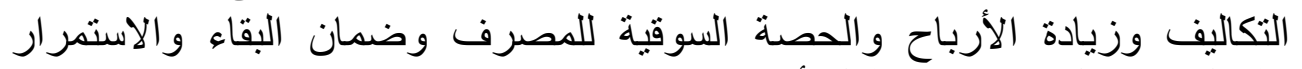

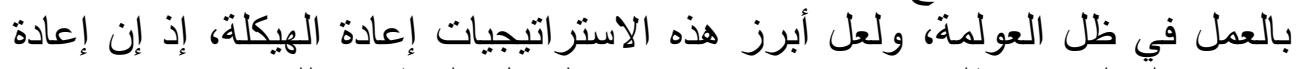

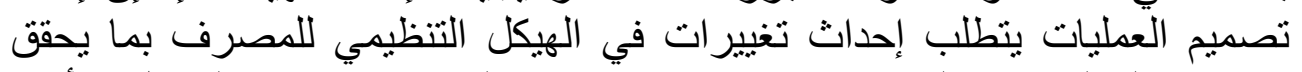

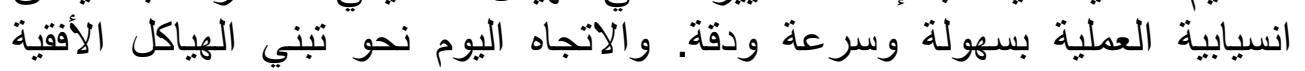

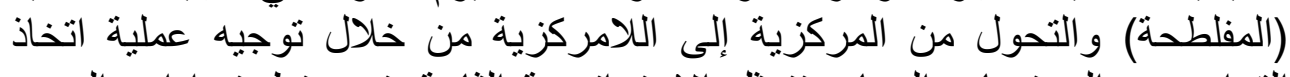

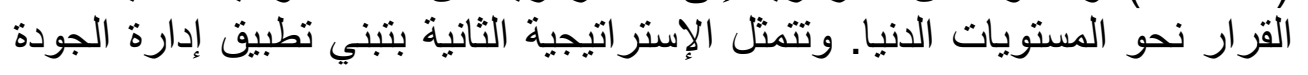


الشاملة على الخدمات المصرفية المقدمة والتي تعد من أهم متطلبات تطبيق إعادة

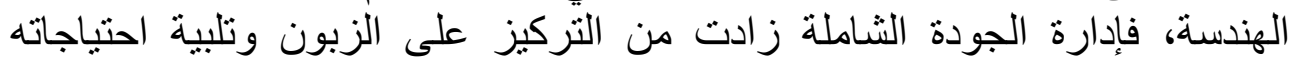

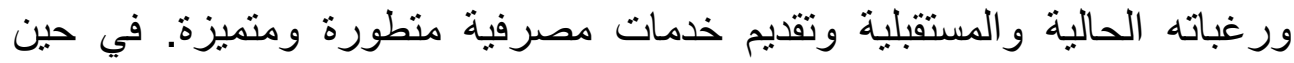

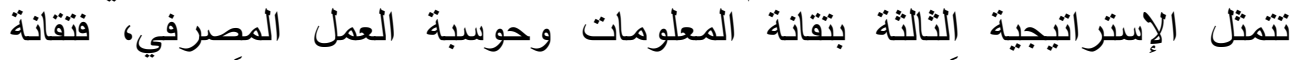

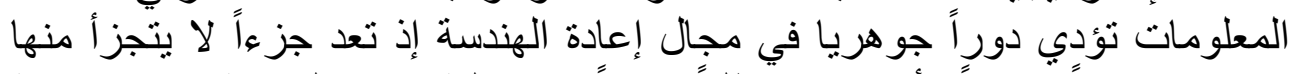

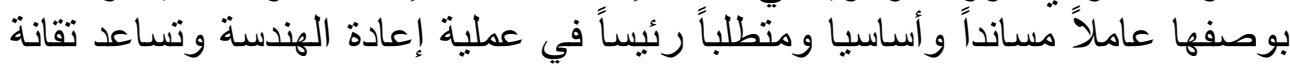

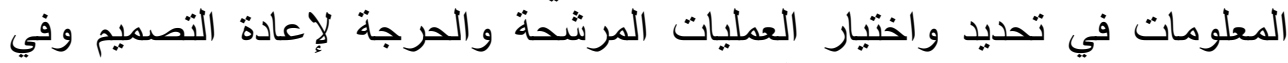

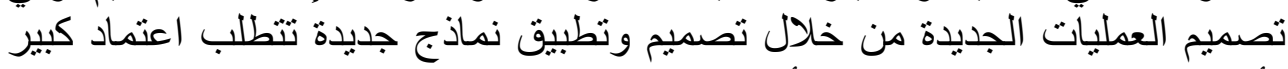

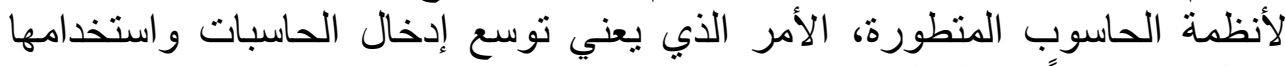
بشكل واسع جداً في العمل المصرفي.

وسنعرض لكل من إعادة الهيكلة وإدارة الجودة الشاملة وحوسبة العمل المصرفي بشيع من التقصيل

\section{أولاًا إستراتيجية إعادة الهيكلة}

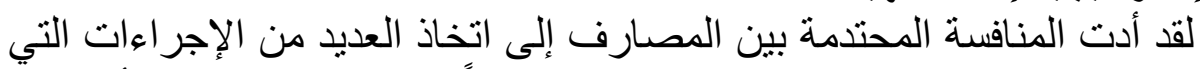

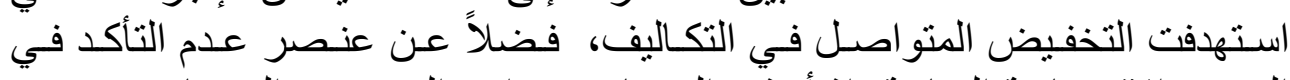

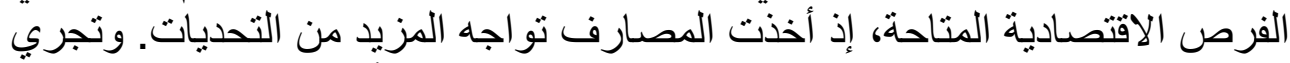

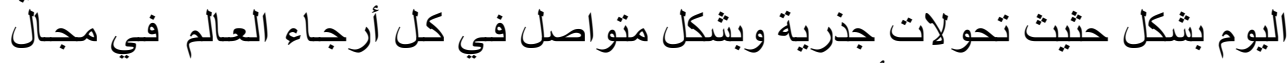

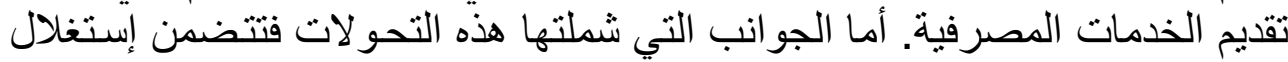

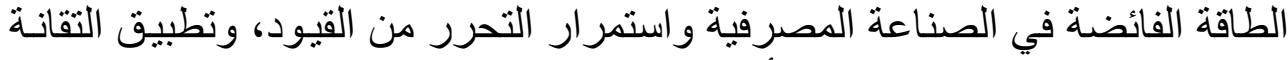

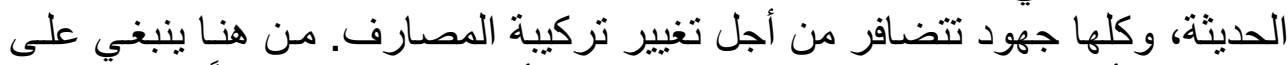

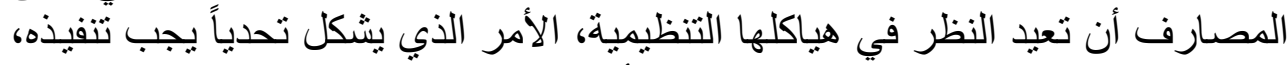

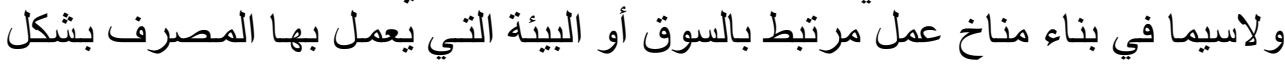

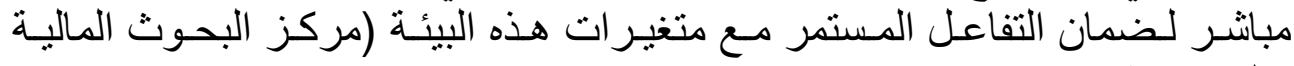

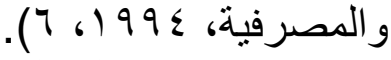

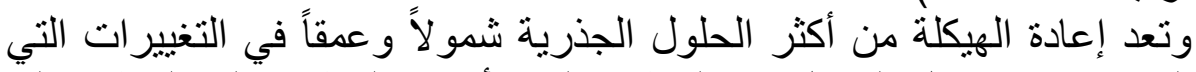

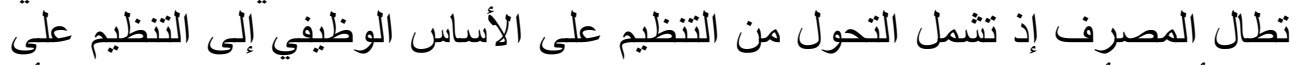

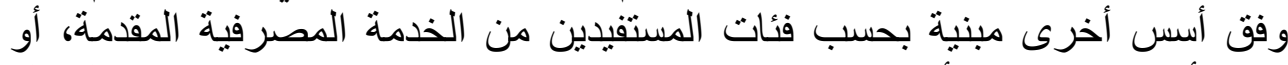

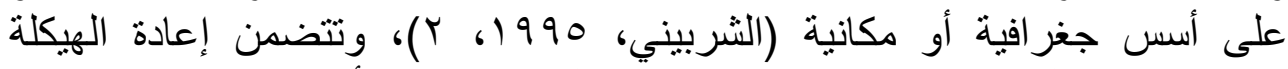

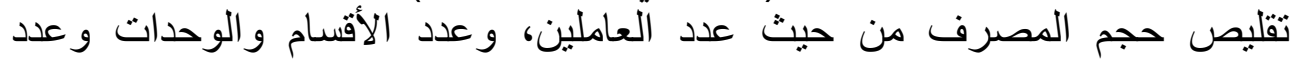

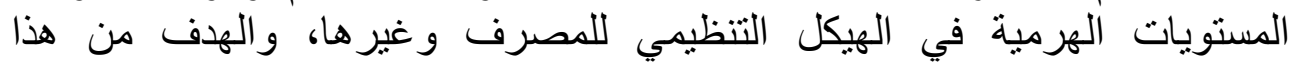
التخفيض في الحجم تحسين كل من الكفاءة و الفاعلية (David, 2001, 249).

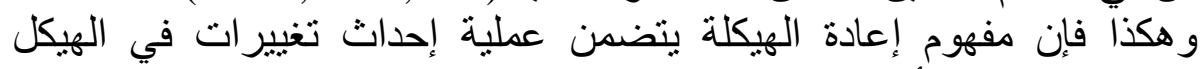

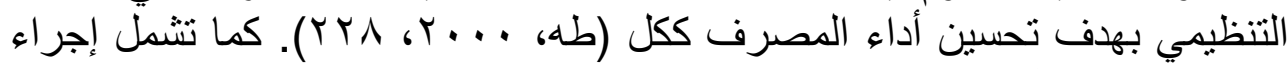

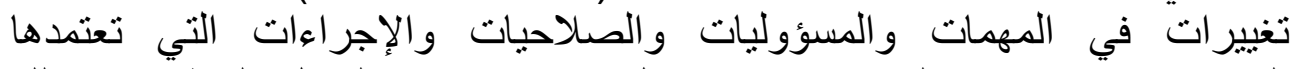
المصارف. وتتم هذه التغييرات من خلال إعادة تصميم الهيكل التنظيمي، وذلك لتهات 


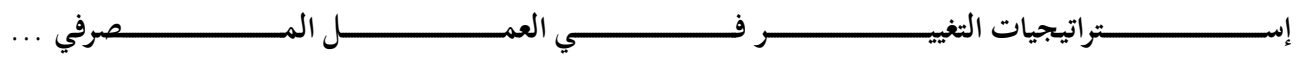

باستحداث وحدات أو أقسام جديدة أو دمج بعض الأقسام القائمة في قسم جديد و إلغاء

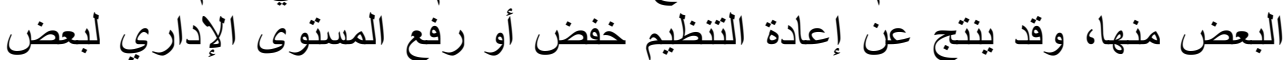

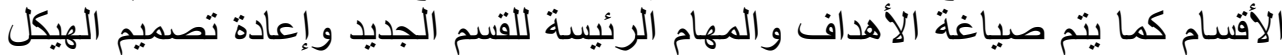

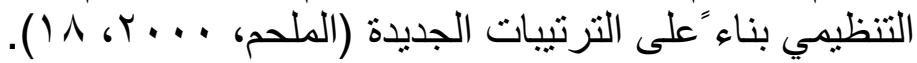

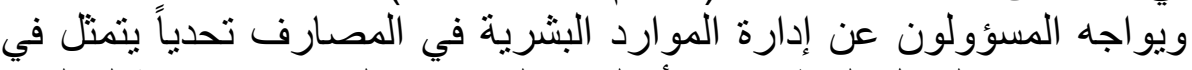

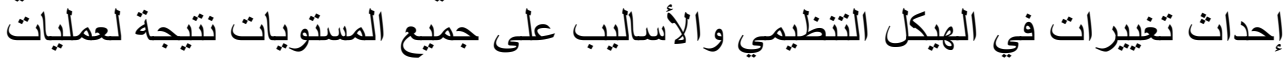

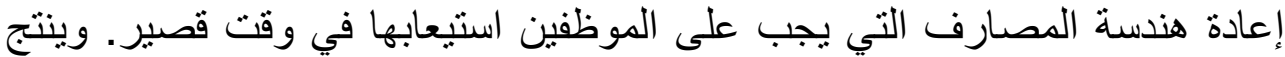

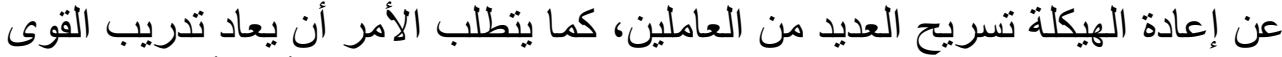

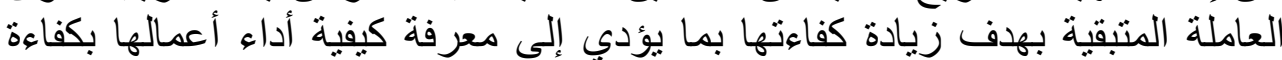
(Jones \& George, أعلى، إلى جانب تعلم مهار ات جديدة في ظل الهيكلة الجديدة

وينبغي أن تهدف إعادة الهيكلة إلى تحقيق هدفين رئيسين يرتبطان بالعمليات

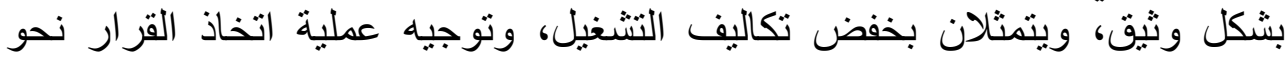

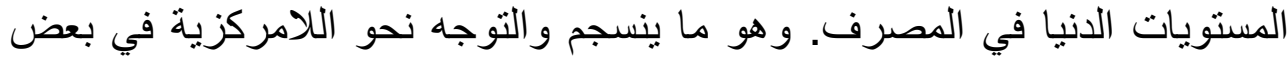
جوانب العمل المصرفي التي تتطلب سرعة اداء العمليات المصرفية بهدف إرضاء وهكا نرى أن الهياكل التنظيمية القديمة والقائمة على الهرمية تستبدل اليوم

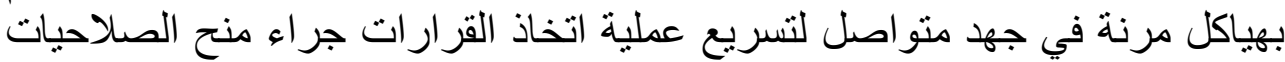
للمستويات الأدنى. وينبغي ان يصاحب ذللك وجود نظم مرنة للمكآفات والحوافز تتناسب مع الطبيعة المتفاوتة للعمليات المصرفية ونية والمالية، مع التأكيد على مكأفاة

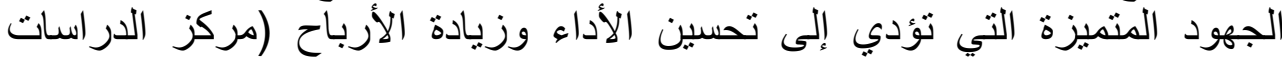

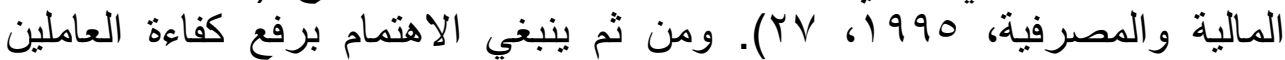
وصقل خبراتهم من خلال الدورات التدريبية المتخصصة وتحديث نظم الته الإدارة

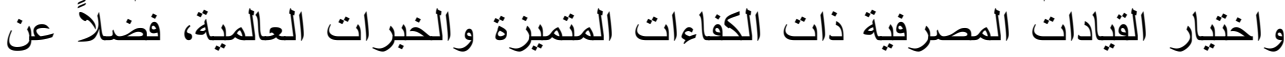

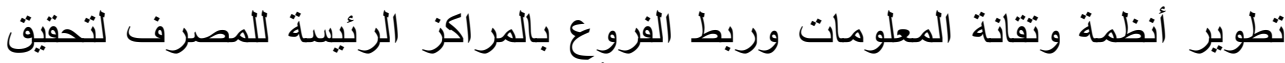

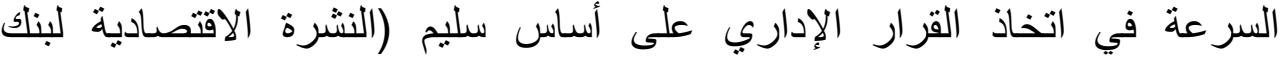

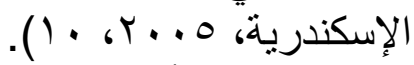

وتعود الأسباب وراء تبني إعادة الهيكلة إلى حاجة المصارف إلى تخفيض

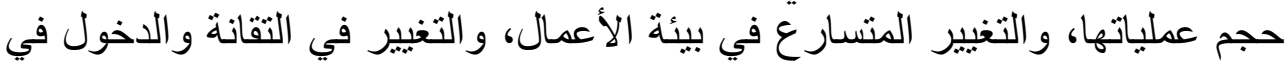

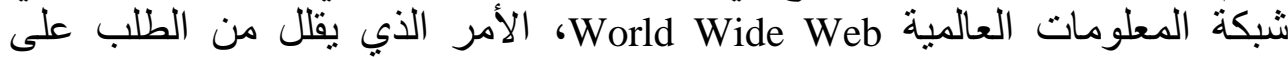

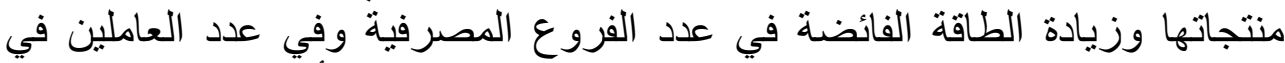

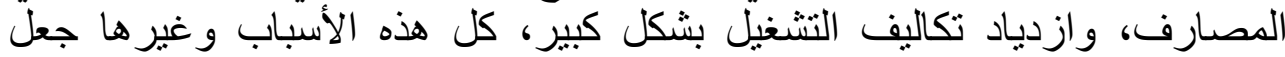

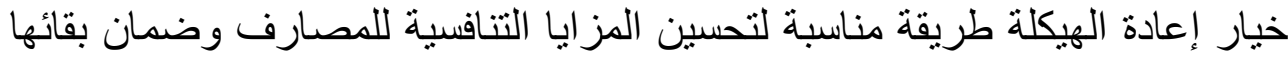

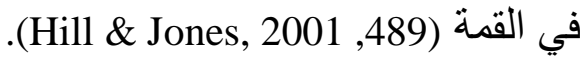

ثانياً- إدارة الجودة الشاملة (TQtal Quality Management) (TQM) 
ينظر إلى إدارة الجودة الثاملة على أنها نظام متكامل لعمليات وأنشطة

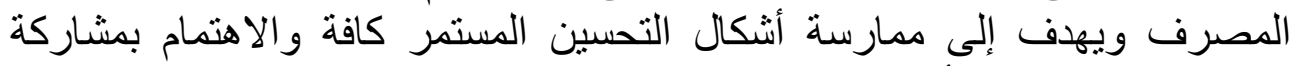

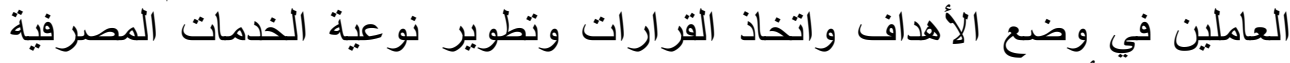

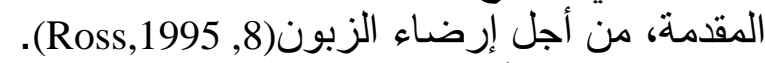
وتعَرف بأنها المدخل إلى تطونى تلرير مراحل الأداء المصرفي المتكامل كافة

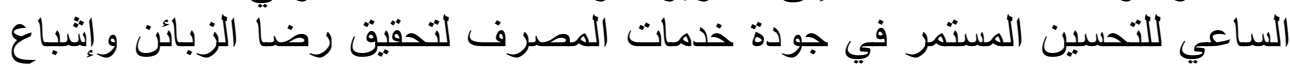

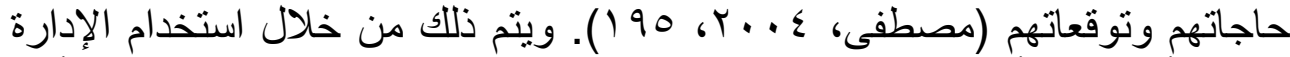

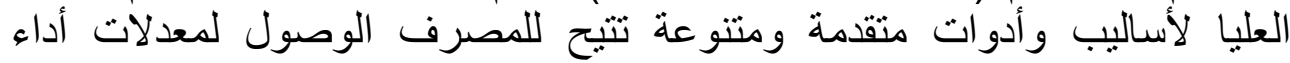

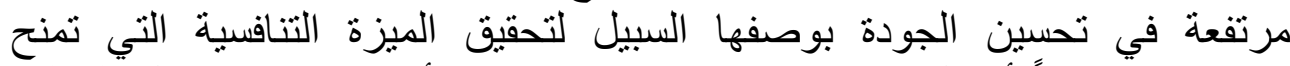

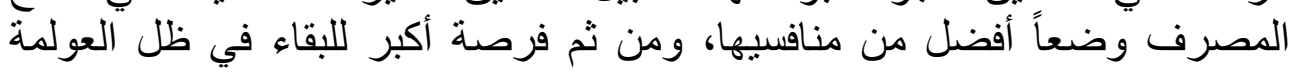

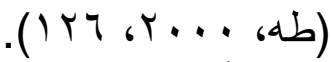

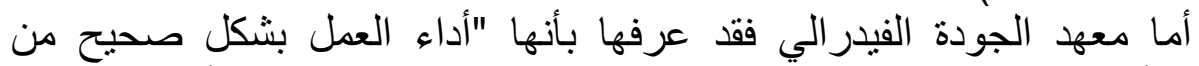
الوهلة الأولى، مع اعتماد على تقييم الزبون لمعرفة مدى لعى تحسين الأداء (هيجان، . ( $)$ ) $6199 \varepsilon$ وتسعى المصارف اليوم إلى تحقيق الجودة الثاملة في الخدمات التي تقدمها،

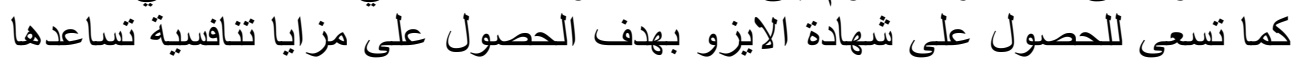

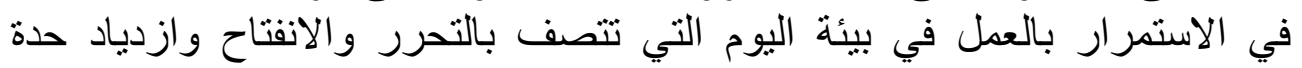

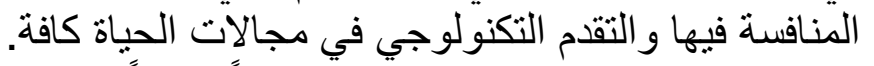

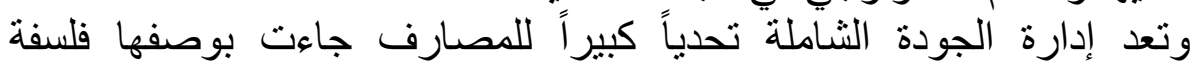

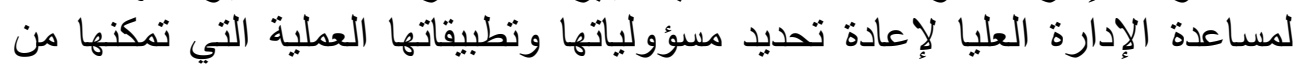

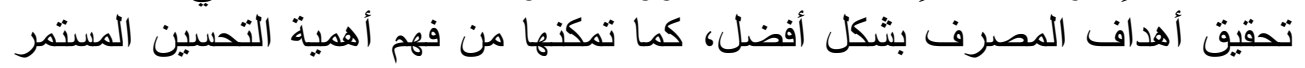

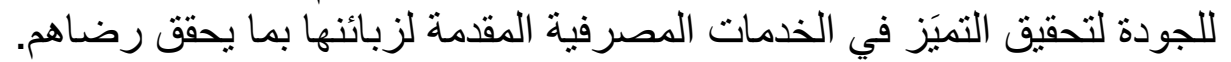

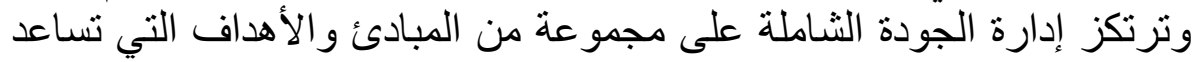

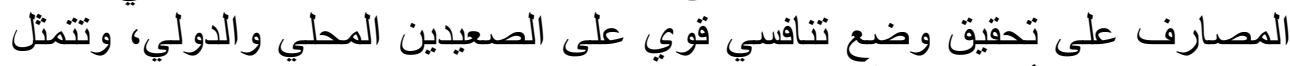

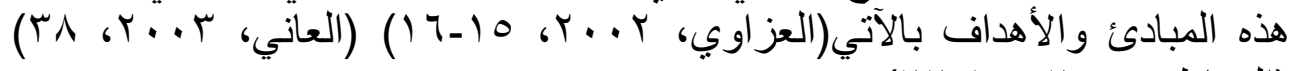

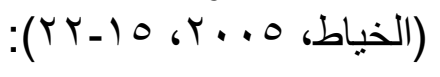

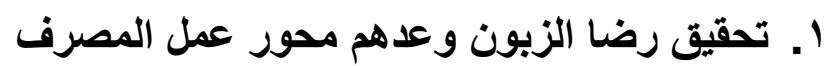

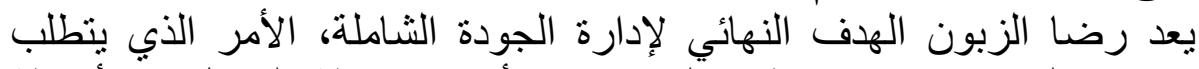

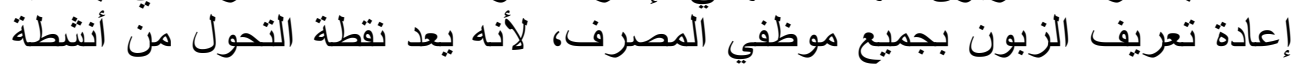

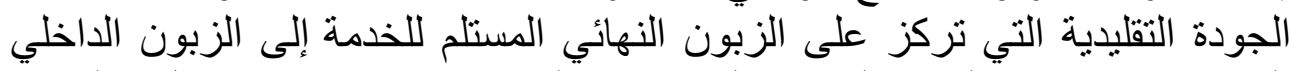

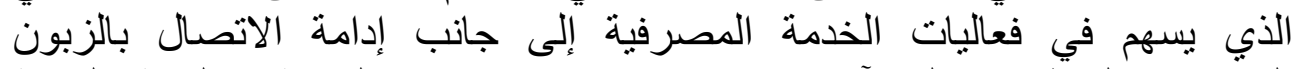

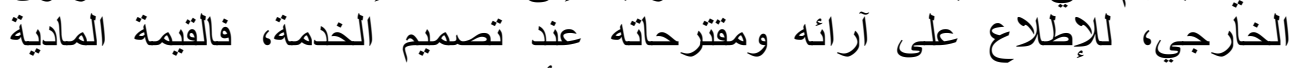
و المعنوية التي يقدمها المصرف لزئ لزبونه تعد الأساس المهم لتلبية متطلبات الجية الجودة 


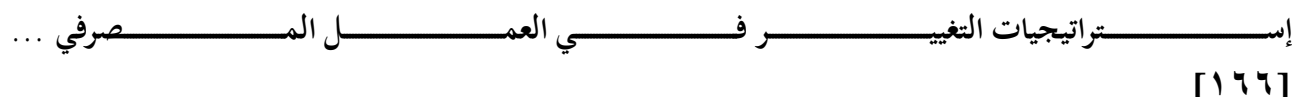

الثاملة. وبهذا بعد الزبون محور عمل المصرف باعتبار أن إدارة الجودة تضع

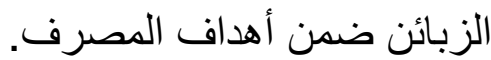
r. مشاركة العاملين في الإدارة واتخاذ واتخاذ القرارات

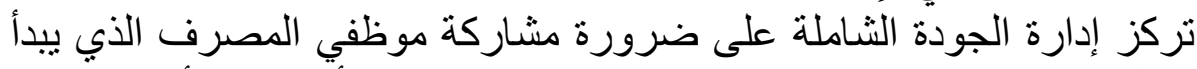

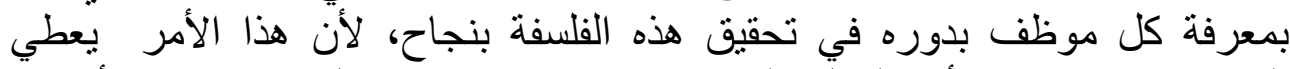

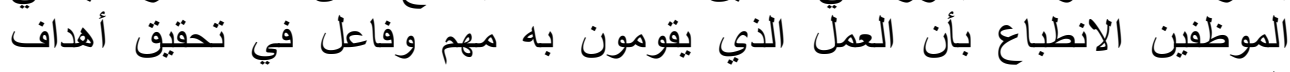

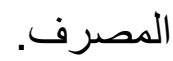

r. التحسين المستمر للخدمة المصرفية

ويتمثل بالبحث المستمر عن الطرق التي تغيّر العملية المصرفية نحو الأفضل.

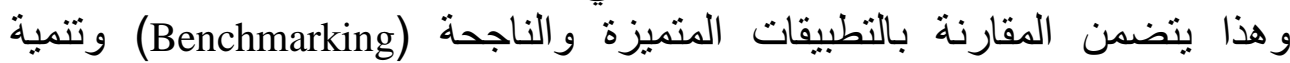

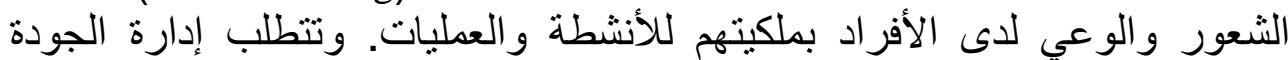

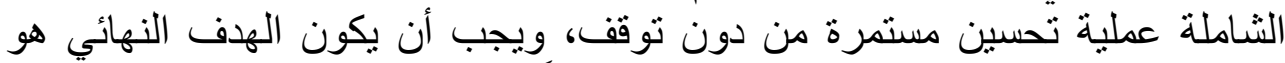

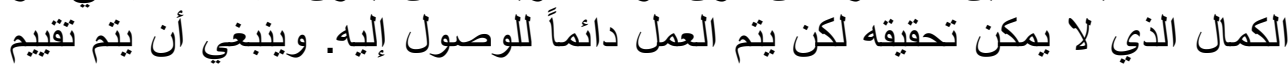
عملية التحسين المستمر كي لا يقع المصرف في إخفاقات وسلبيات مكلفة بالنسبة

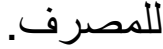

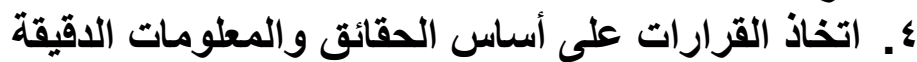

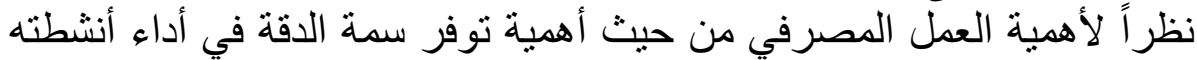

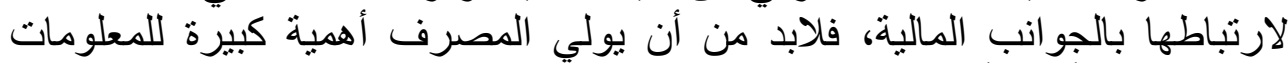

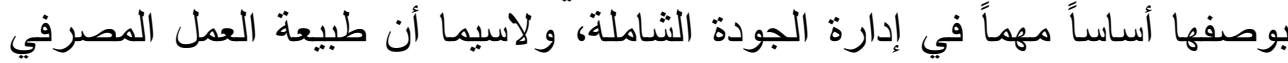

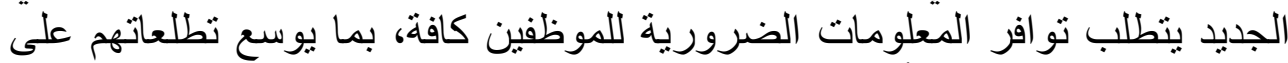

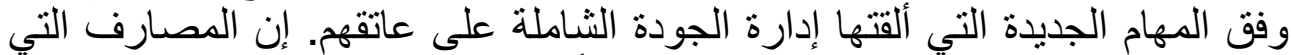

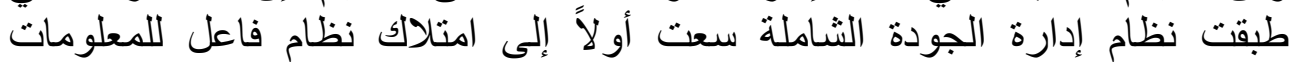

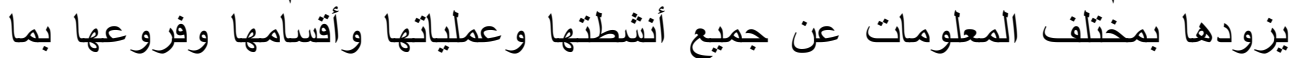

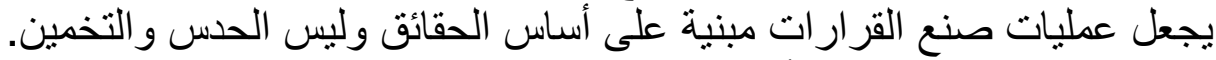

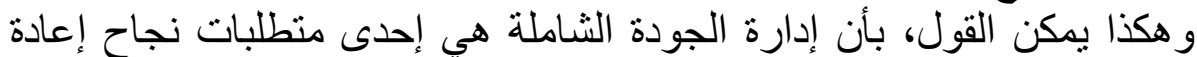

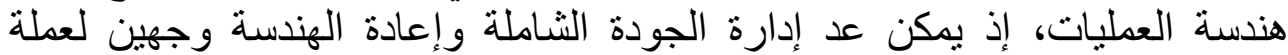

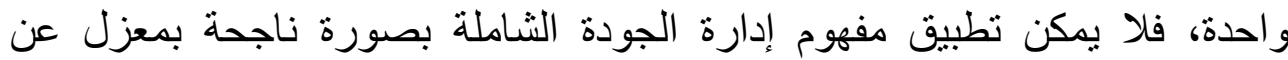

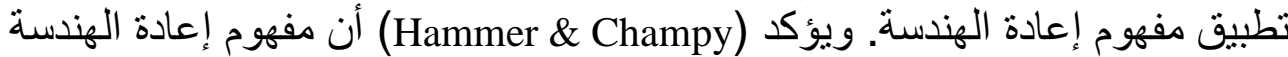

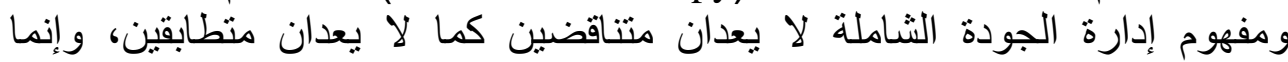

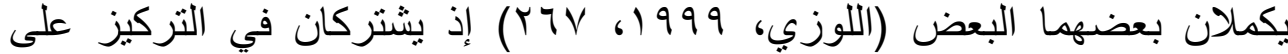

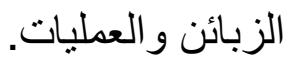

ثالثاً. تقانة المعلومات وحوسبة العمل المصرفي

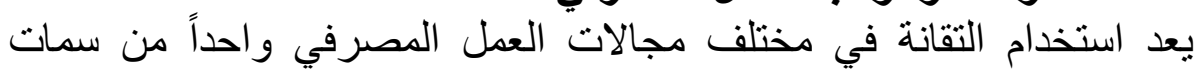

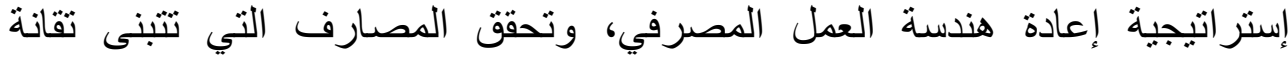
المعلومات الحديثة هدفين رئيسين يتمثلان في: كسب زبائن جدد، والتخفيض التيض المستمر 
في تكاليف الخدمات المصرفية المقدمة، وهكذا أصبح الإنفاق المتواصل على الصى التقانة

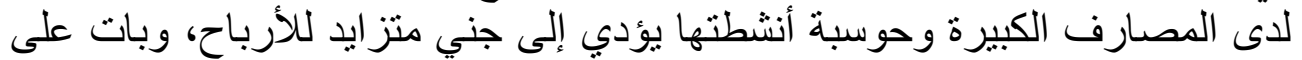

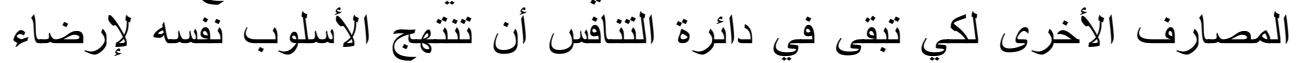

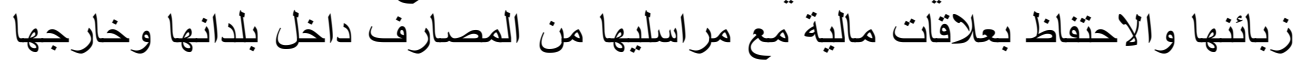

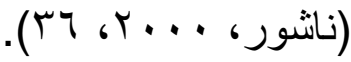

وتشير تقانة المعلومات إلى الأدوات و الأساليب والأجهزة و الطرق المستخدمة

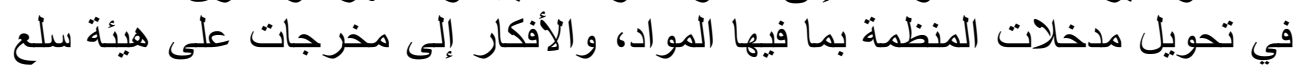
وخدمات (Daft, 2001, 199). كما يمكن النظر إلى تقانة المعلومات المصرفية على أنها قيام المصارف فيتقاتيم

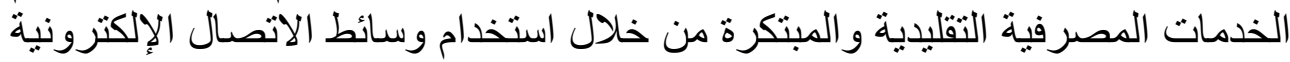

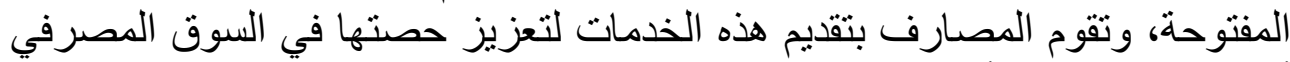

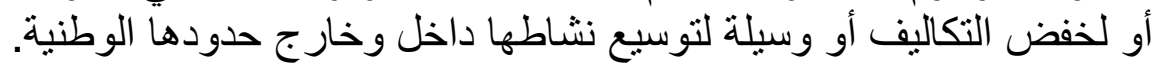

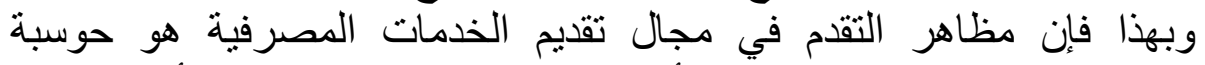

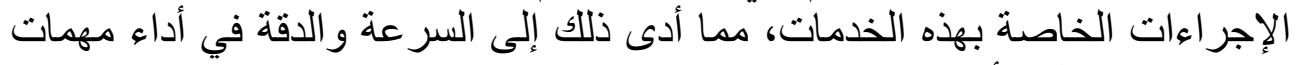

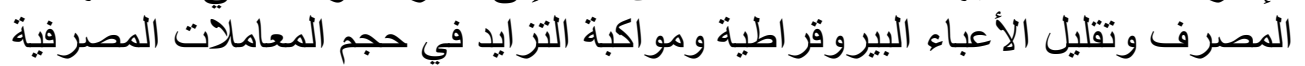

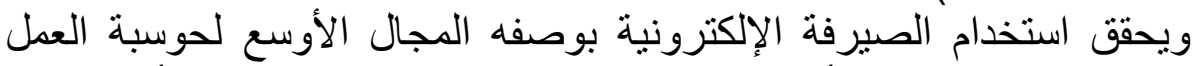

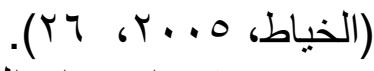

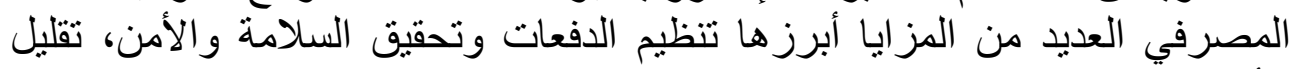

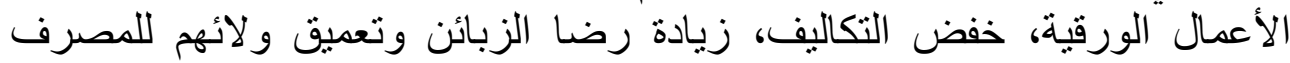

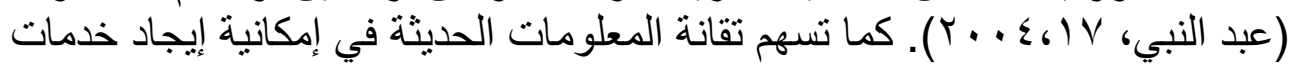
جديدة و إمكانية دعم الموقف التنافسي للمصرف المباف وبناء مجموعة من العقبات التي تمنع

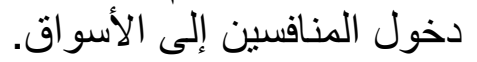
وقد يترتب على استخدام تقانة المعلومات آثناراً مهمة على الأنشطة و الهياكل

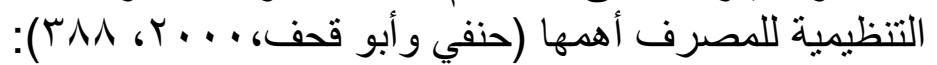
y

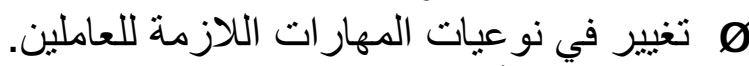

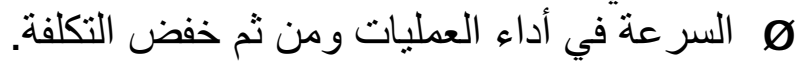

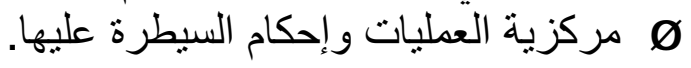

لقد أظهرث مجريات البحثث أن التغيير في ونائر العمل المصرفي بات أمراً النتائج والتوصيات

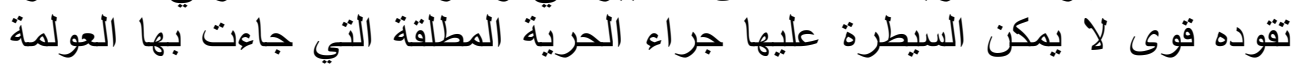

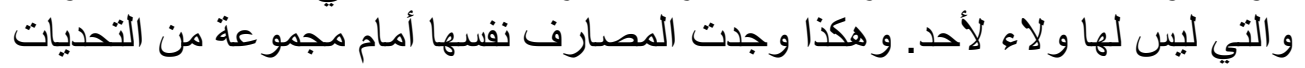

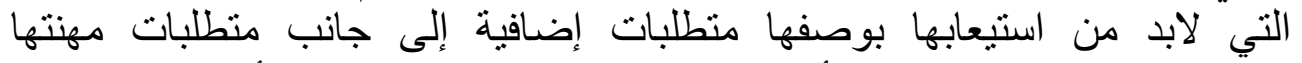

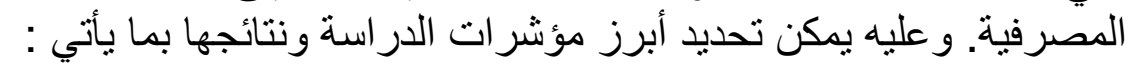




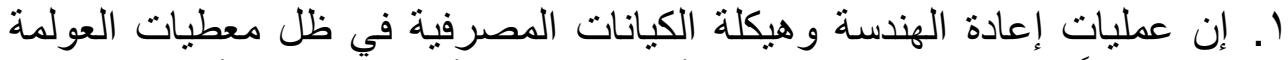

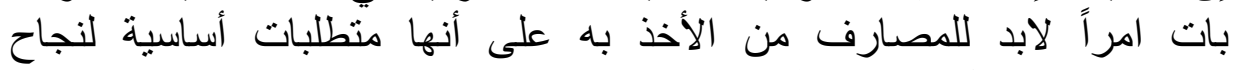

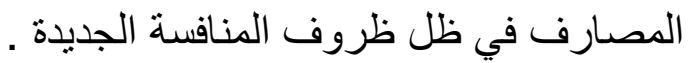

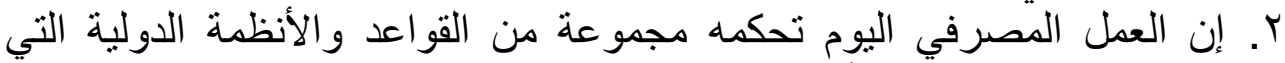

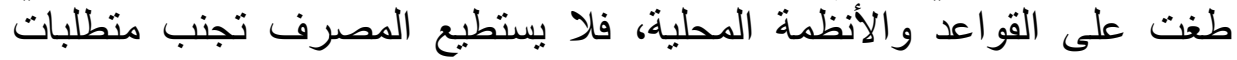

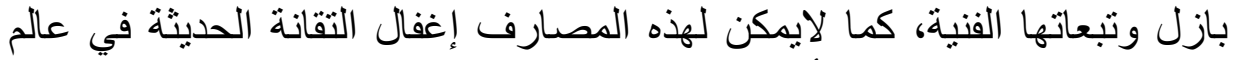

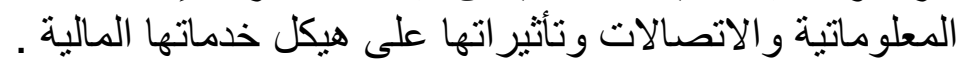

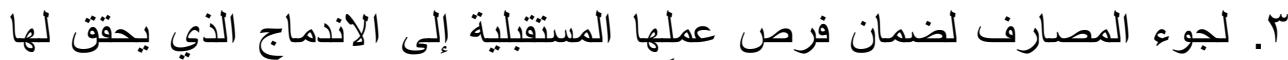

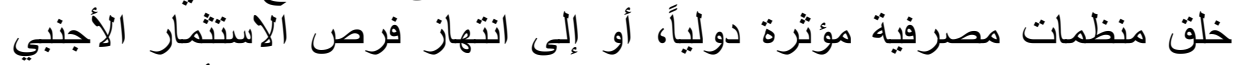

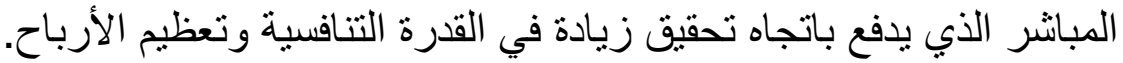

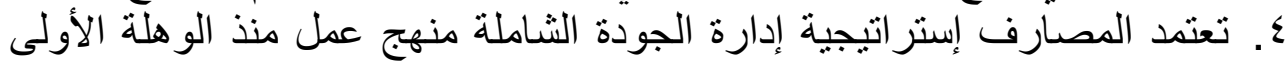

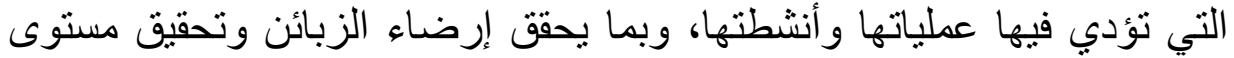
التحسين المستمر للخدمات.

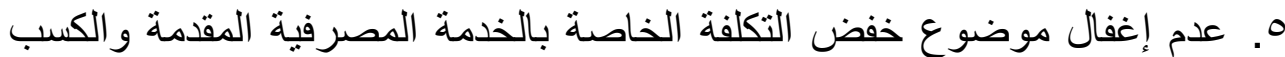

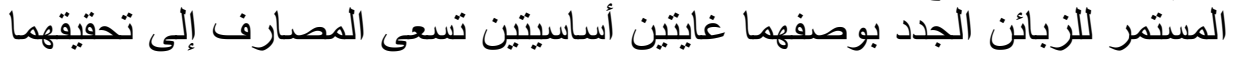

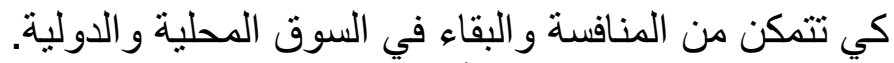

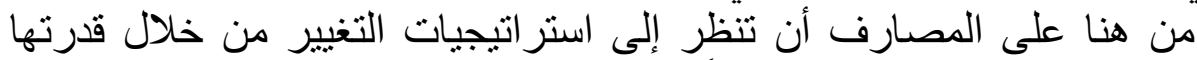

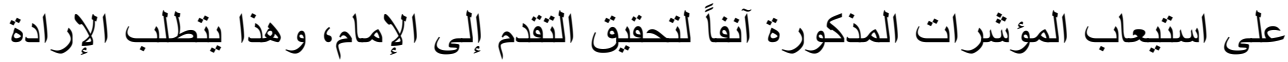

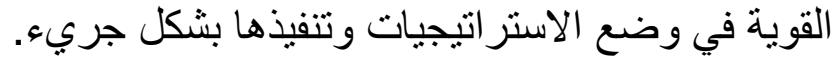

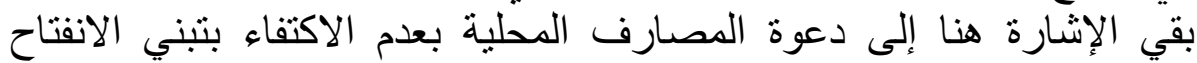

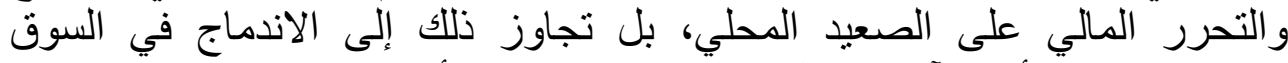

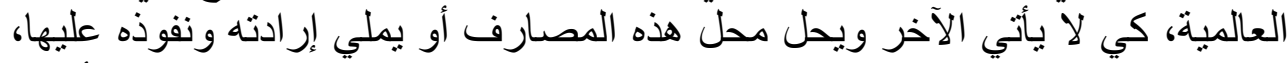

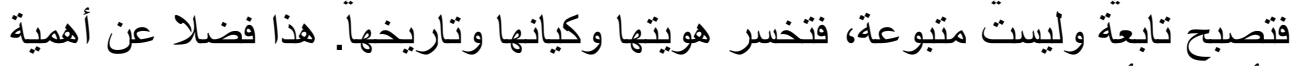

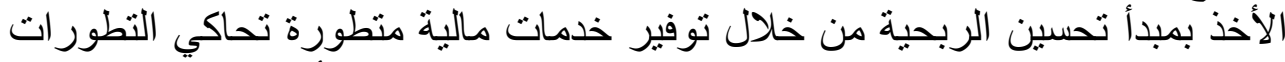

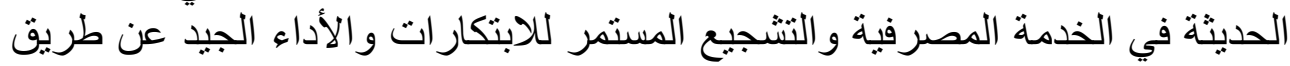
تدريب وتطوير الكفاءات الموجودة وتوظيف الكفاءاء الكية العلمية المتميزة.

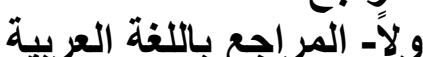

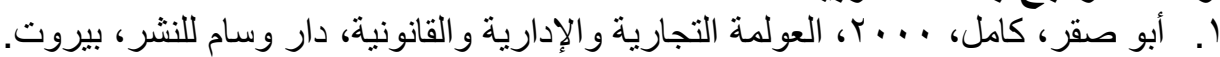

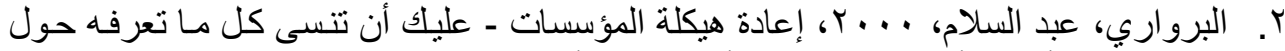

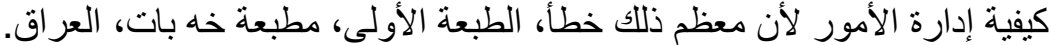

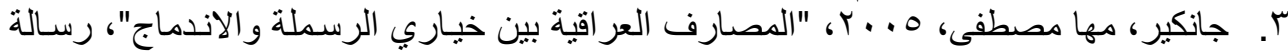

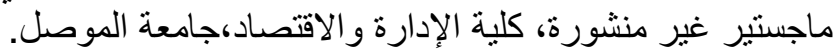

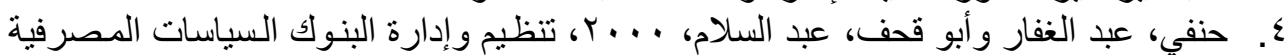

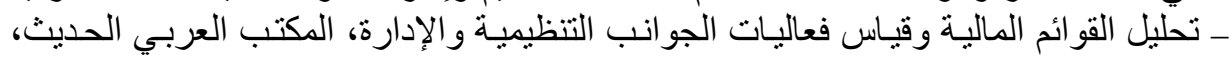




\section{الاكتور السيدية ومحمد [9 97 ]}

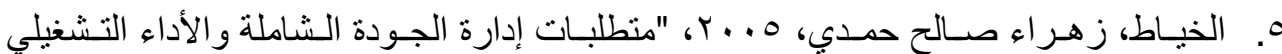

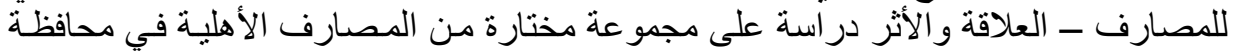

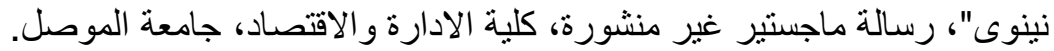

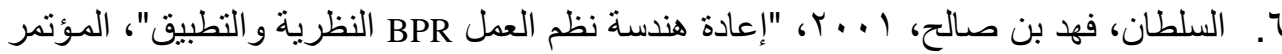

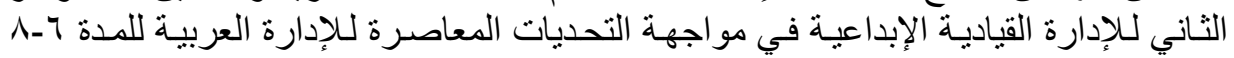

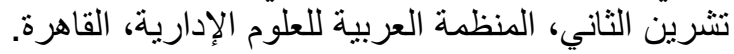

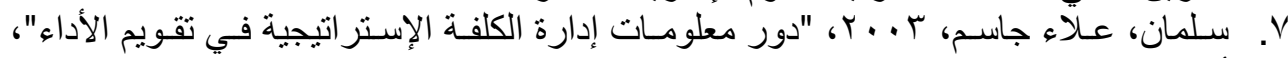

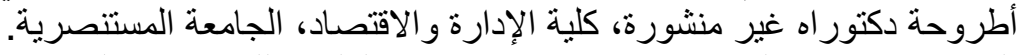

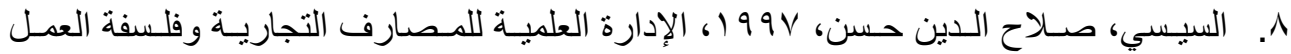

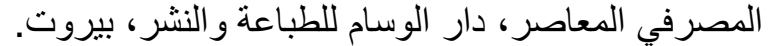
9 9. الثربيني، عبد العزيز، 990 19، "المداخل الرئيسية للإصـلاح الإداري"، مجلة إخبار الإدارة،

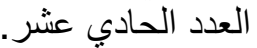

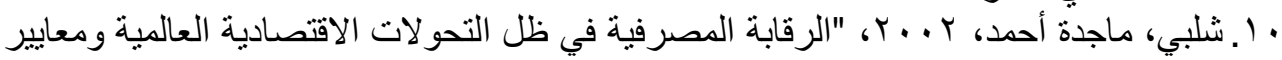

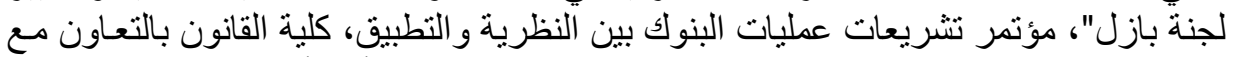

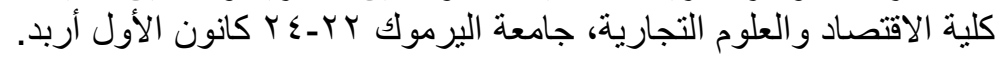

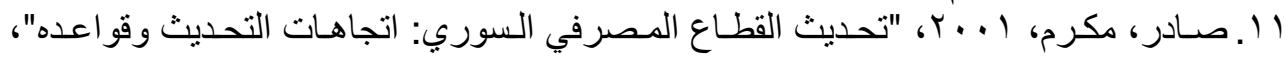

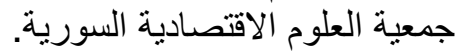

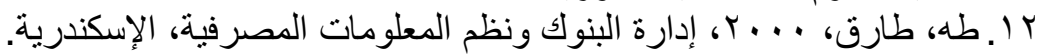

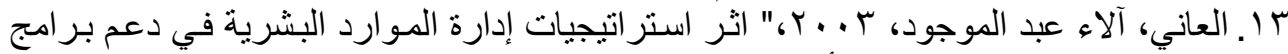

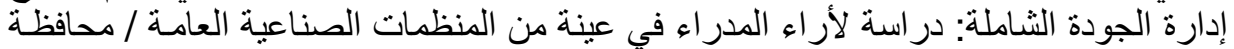

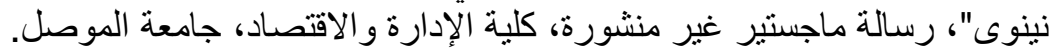

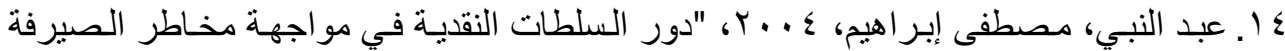

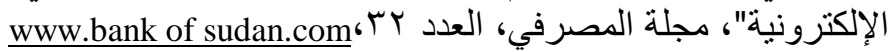

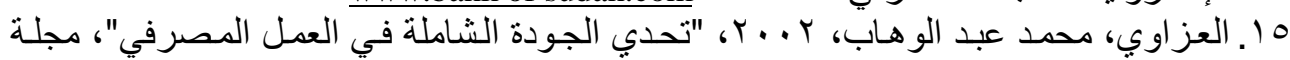

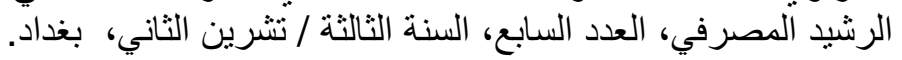

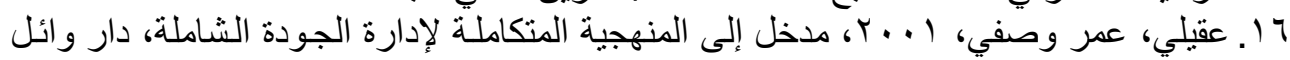

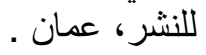
Vا ا.قاحوش، نـادر الفرد، . . . Y، العمل المصرفي عبر الإنترنت، الدار العربيـة للعلوم، مكتبـة

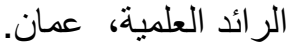

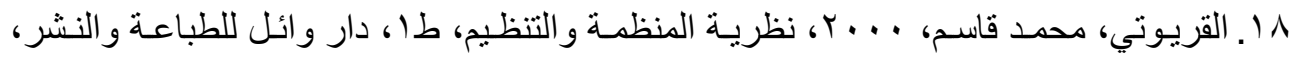

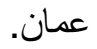

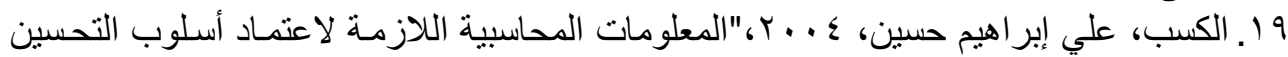

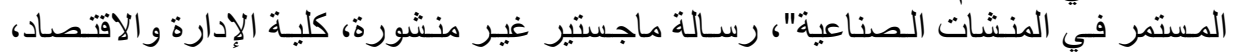

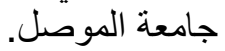
• ץ. اللوزي، موسى، 999 19، التطوير التنظيمي: أساسيات ومفـاهيم حديثة، الطبعة الأولى، دار

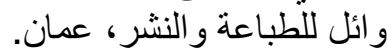

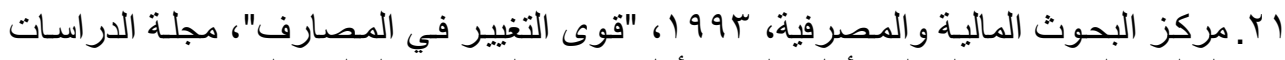

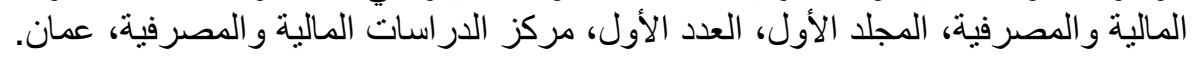

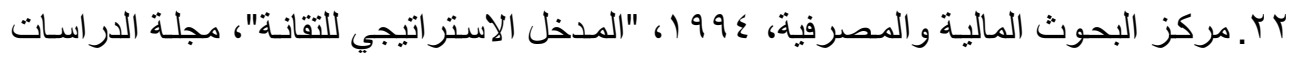

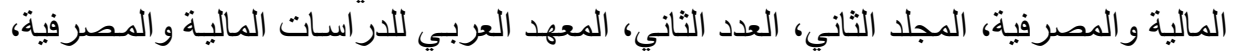




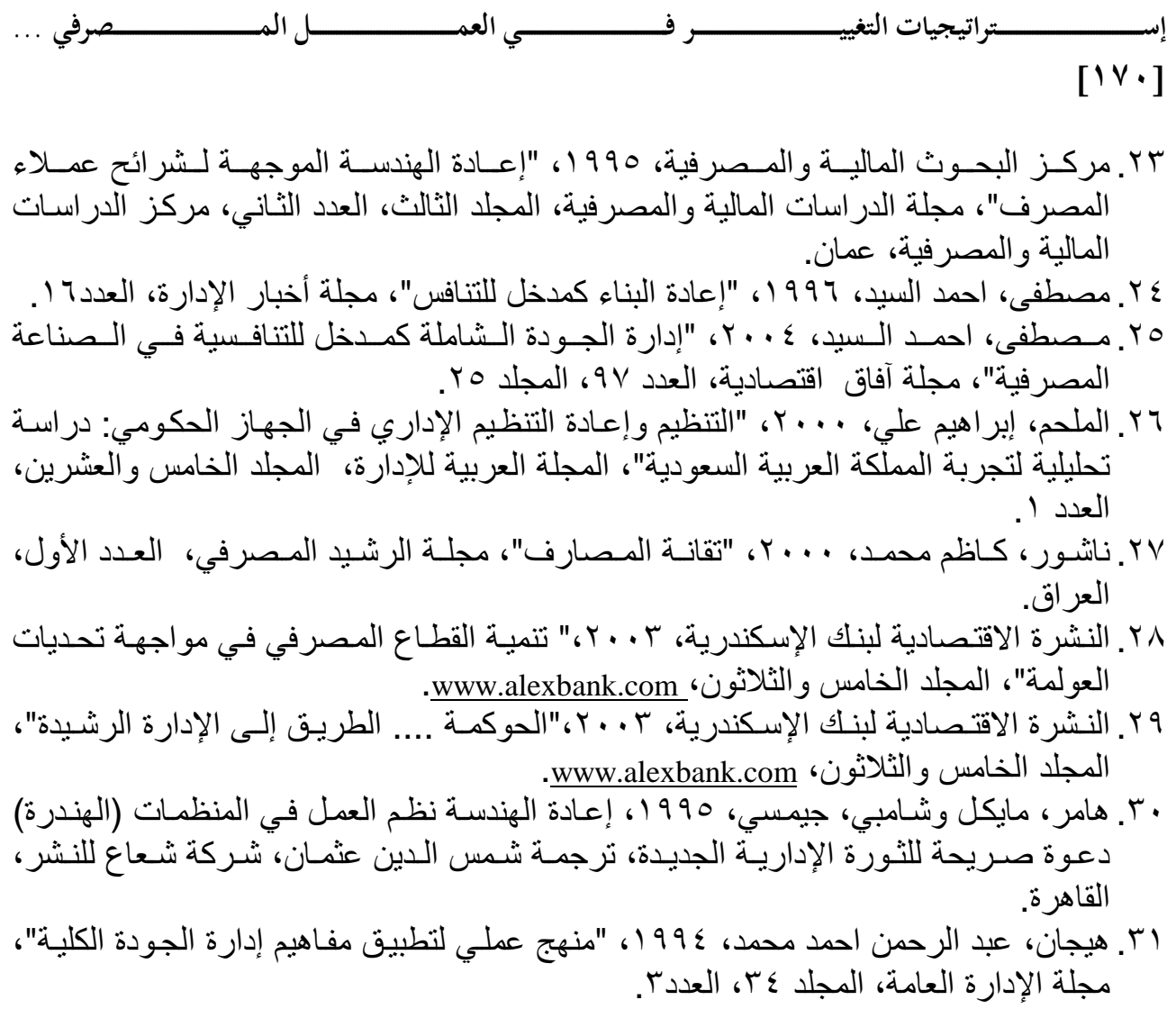

\section{ثانياً. المراجع باللغة الأجنبية}

1. Booz Allen, Hamilton, 2000, Management Century: A Critical Review of 20th Century Though and Practice Stuart Crainer, U.S.A.

2. Charles W. 1. Hill, Gareth R. Jones, 2001، Strategic Management Theory, 5th ed., Houghton Mifflin Company, New York, U.S.A.

3. Fred R.David, 2001, Strategic Management Concepts \&Cases, $8^{\text {th }}$ ed., Prentice Hall,U.S.A.

4. Jennifer M. George, Goreth R. Jones, 1999, Organizational Behavior, $2^{\text {nd }}$. ed., U.S.A.

5. Richard L. Daft, 2001, Organization Theory and Design, South-western College Publishing, Ohio, U.S.A.

6. Ross, J. E., 1995, Total Quality Management: Cases \& Reading, $2^{\text {nd }}$.ed., St. Lucie Press, U.S.A. 